\title{
1,3,4-Thiadiazole-Containing Azo Dyes: Synthesis, Spectroscopic Properties and Molecular Structure
}

\author{
Agnieszka Kudelko ${ }^{1, * \mathbb{D}}$, Monika Olesiejuk ${ }^{1}{ }^{\mathbb{D}}$, Marcin Luczynski ${ }^{1}$, Marcin Swiatkowski ${ }^{2} \mathbb{D}$, \\ Tomasz Sieranski $^{2}$ (D) and Rafal Kruszynski ${ }^{2}$ (D) \\ 1 Department of Chemical Organic Technology and Petrochemistry, The Silesian University of Technology, \\ Krzywoustego 4, PL-44100 Gliwice, Poland; monika.olesiejuk@polsl.pl (M.O.); \\ marcin.luczynski@polsl.pl (M.L.) \\ 2 Department of X-ray Crystallography and Crystal Chemistry, Institute of General and Ecological Chemistry, \\ Lodz University of Technology, Żeromskiego 116, PL-90924 Łódź, Poland; \\ marcin.swiatkowski@p.lodz.pl (M.S.); tomasz.sieranski@p.lodz.pl (T.S.); rafal.kruszynski@p.lodz.pl (R.K.) \\ * Correspondence: agnieszka.kudelko@polsl.pl; Tel.: +48-32-237-17-29
}

Academic Editors: Jorge Bañuelos Prieto and Ugo Caruso

Received: 10 June 2020; Accepted: 13 June 2020; Published: 18 June 2020

check for updates

\begin{abstract}
Three series of azo dyes derived from 2-amino-5-aryl-1,3,4-thiadiazoles and aniline, $N, N$-dimethylaniline and phenol were synthesized in high yields by a conventional diazotization-coupling sequence. The chemical structures of the prepared compounds were confirmed by ${ }^{1} \mathrm{H}-\mathrm{NMR},{ }^{13} \mathrm{C}-\mathrm{NMR}, \mathrm{IR}, \mathrm{UV}$-Vis spectroscopy, mass spectrometry and elemental analysis. In addition, the $\mathrm{X}$-ray single crystal structure of a representative azo dye was presented. For explicit determination of the influence of a substituent on radiation absorption in UV-Vis range, time-dependent density functional theory calculations were performed.
\end{abstract}

Keywords: heterocycles; 2-arylazo-5-aryl-1,3,4-thiadiazoles; azo-coupling reactions; crystal structure

\section{Introduction}

Thiadiazoles are five-membered heterocyclic arrangements which are rarely found in nature. Nitrogen, sulfur and carbon atoms can be arranged in several different ways in such a ring, which gives rise to several isomers: 1,2,3-thiadiazole, 1,2,4-thiadiazole, 1,2,5-thiadiazole and 1,3,4-thiadiazole [1,2]. Of these four isomers, derivatives of 1,3,4-thiadiazole seem to be the most popular among scientists. Many compounds containing such a scaffold exhibit a broad spectrum of biologic interactions and have been shown to have antifungal [3,4], antimicrobial [5], anti-inflammatory [6] and anticancer activities [7]. As well as other industrial applications, it is worth mentioning their use as viscosity stabilizers in rubber processing [8], additives for the production of lithium battery electrodes [9], dyes [10] and optoelectronic materials [11]. There are also reports of the applications of 1,3,4-thiadiazole derivatives, in particular 2,5-dimercapto-1,3,4-thiadiazoles, as lubricants [12].

Azo dyes, characterized by the presence of azo moiety $(\mathrm{N}=\mathrm{N})$ in their structure, are the most essential group of disperse dyes [13]. They have found a broad application mainly in dyestuff industry, but also in food, cosmetics and pharmaceuticals production. Generally azo dyes exhibit excellent coloring properties and offer vivid colors, starting from yellows, through oranges, reds and ending up in blues. One of the subgroups of this family are conjugated 1,3,4-thiadiazoles containing an azo group $(\mathrm{N}=\mathrm{N})$ in their structure. Such heterocyclic azo disperse dyes have received attention from the scientific community due to their brightness, clarity and affinity to various fibers $[14,15]$. The most common methodology to introduce this type of group into a final azo compound is a two-step transformation through appropriate diazonium salts [16]. The latter are usually produced from the reaction of primary aromatic amines with nitrites in the presence of strong mineral acids at 
low temperatures. Due to the extreme instability of diazonium salts [17], they are used immediately after their formation in coupling reactions with phenols or amines, substituted with electron-donating groups. Other methods used to prepare azo dyes include the condensation of nitro compounds with amines [18], reduction of nitro compounds [19,20], oxidation of amines [21,22] or condensation of nitroso compounds with amines [23]. In contrast to typical aromatic amines, diazotization and subsequent coupling of 1,3,4-thiadiazole-2-amine derivatives is rarely described in the literature [24-26], although thiadiazoles contain an important thiazole chromophoric core in their structure. This may be due to the presence of an additional electronegative nitrogen atom, which decreases the basicity of the external amino group and reduces its reactivity.

In continuation of our study on the synthesis and versatile applications of conjugated 1,3,4-thiadiazole derivatives [27-29], we attempted to synthesize and characterize the structural features of a new series of 2-phenylazo-1,3,4-thiadiazoles, functionalized with aryl substituents directly on the heterocyclic ring. Such systems combining the 1,3,4-thiadiazole ring with other aromatic compounds through an azo linker may find potential industrial applications, not only as classical synthetic dyes and pigments, laser dyes and monomers for the production of OLEDs, but also in medicine and agriculture due to the presence of a toxophoric N-C-S moiety [30].

\section{Results and Discussion}

\subsection{Synthesis}

The starting reagents in the synthesis of 1,3,4-thiadiazole-containing azo dyes were commercially available aromatic carboxylic acids substituted at position 4 with electron-donating or withdrawing groups (1a-e, Scheme 1). They were heated with thionyl chloride $\mathrm{SOCl}_{2}$ and the resulting crude acid chlorides were transformed into derivatives of 2-benzoylhydrazinecarbothioamide (2a-e) in a two-phase water-toluene solvent system in the presence of base $\left(\mathrm{NaHCO}_{3}\right)$. The resulting acyclic intermediates underwent cyclization in concentrated sulfuric acid to give the desired 2-amino-5-aryl-1,3,4-thiadiazoles (3a-e). The next stages in the few-step reaction sequence were the diazotization of 2-amino-1,3,4-thiadiazole derivatives (3a-e) and the subsequent coupling of the diazonium salts formed from aniline, $N, N$-dimethylaniline and phenol (Scheme 1). Diazotization involved the reaction of a primary heteroaromatic amine (3a-e) with a nitrosating agent (nitrosyl cation) generated in situ from sodium nitrite and concentrated sulfuric acid at low temperatures. Reactions were performed in a mixture of glacial acetic acid and propionic acid in order to improve the solubility of the starting thiadiazoles. An excess of nitrous acid in the post-reaction mixture was detected with potassium iodide-starch study and eliminated by adding urea. The resulting colored diazonium salts were then used directly without purification in the coupling sequence with aromatic amines: aniline $\left(\mathrm{G}=\mathrm{NH}_{2}\right)$ and $N, N$-dimethylaniline $\left(\mathrm{G}=\mathrm{NMe}_{2}\right)$ and with phenol $(\mathrm{G}=\mathrm{OH})$. Due to the limited stability of diazonium salts, the transformations were carried out at low temperatures $\left(0-5^{\circ} \mathrm{C}\right)$ and the final products were precipitated from solution by adding base $\left(\mathrm{Na}_{2} \mathrm{CO}_{3}\right)$ after reagents were combined. The reactions resulted in the formation of three series of 2-arylazo-5-aryl-1,3,4-thiadiazole dyes in various yields (4a-e, 5a-e, $\mathbf{6 a}-\mathbf{e}$, Scheme 1). The highest yields were obtained from the transformations involving phenol (6a-e, 75-91\%, Scheme 1), while the reactions using $N, N$-dimethylaniline (5a-e, 56-69\%, Scheme 1$)$ and aniline (4a-e, 51-81\%, Scheme 1) produced lower yields. Such situation may be caused by partial deactivation of anilines in acidic media. Generally, 1,3,4-thiadiazole-containing azo dyes are high-melting solids (melting point range $169-293^{\circ} \mathrm{C}$ ) and are insoluble in both water and hydrocarbons (hexane, toluene). They are highly soluble in DMSO, acetone and methanol. It is worth noting that among the synthesized derivatives, 12 are new compounds not yet described in the literature. 


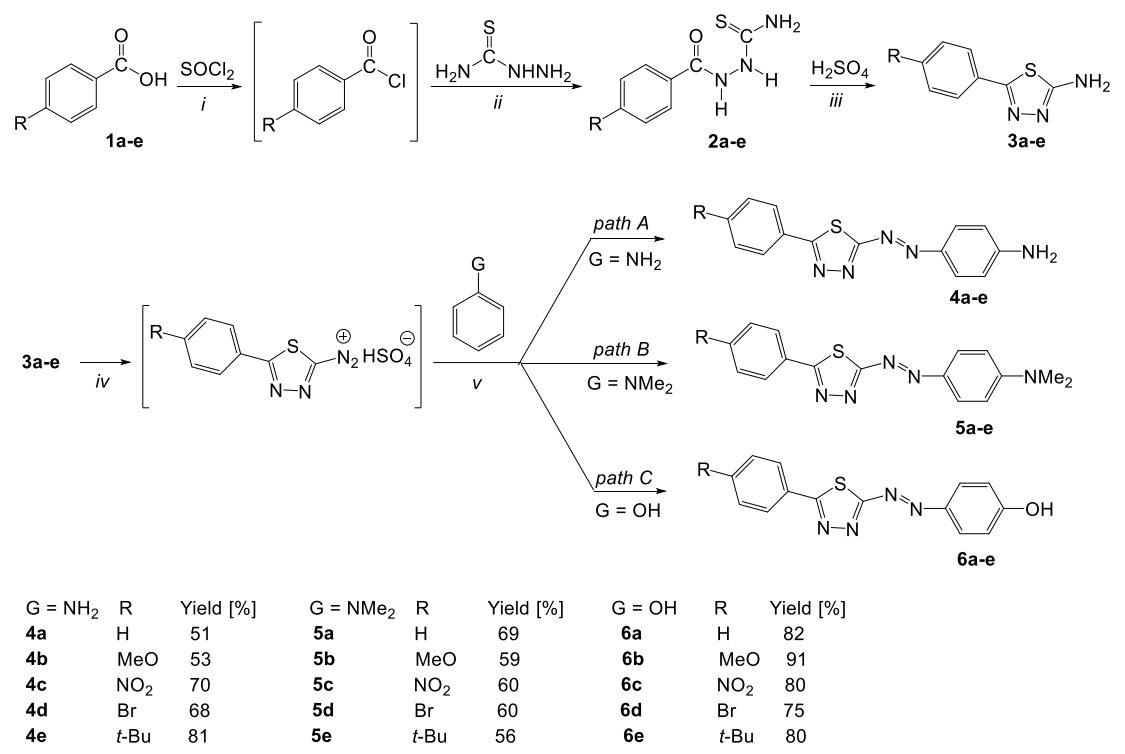

Scheme 1. Preparation of 2-amino-1,3,4-thiadiazole precursors (3a-e) and synthesis of 2-arylazo-5-aryl-1,3,4-thiadiazole dyes (4a-e, 5a-e, 6a-e). Reaction conditions: (i) toluene, reflux, 5-15 h; (ii) toluene, $\mathrm{NaHCO}_{3}, \mathrm{H}_{2} \mathrm{O}, \mathrm{rt}, 24 \mathrm{~h}$; (iii) conc. $\mathrm{H}_{2} \mathrm{SO}_{4}, 24 \mathrm{~h}$ and then aqueous $\mathrm{NH}_{3}$; (iv) $\mathrm{NaNO}_{2}$, conc. $\mathrm{H}_{2} \mathrm{SO}_{4}, \mathrm{AcOH} / \mathrm{EtCOOH}, 0-5{ }^{\circ} \mathrm{C}$; (v) $\mathrm{H}_{2} \mathrm{O}, 0-5{ }^{\circ} \mathrm{C}$ and then $\mathrm{Na}_{2} \mathrm{CO}_{3}$.

\subsection{Spectral Characterization}

The structures of the final diazotization products of 2-amino-5-aryl-1,3,4-thiadiazole and their subsequent coupling with aniline, $N, N$-dimethylaniline and phenol were confirmed by typical spectroscopic methods $\left({ }^{1} \mathrm{H}-\mathrm{NMR},{ }^{13} \mathrm{C}-\mathrm{NMR}, \mathrm{UV}-\mathrm{Vis}, \mathrm{FT}-\mathrm{IR}\right.$ and HRMS). In the ${ }^{1} \mathrm{H}-\mathrm{NMR}$ spectra of 2-arylazo-5-aryl-1,3,4-thiadiazoles (4a-e, $\mathbf{5 a}-\mathbf{e}, \mathbf{6 a}-\mathbf{e})$, the characteristic signals become from protons located in the benzene rings associated with the 1,3,4-thiadiazole core and appeared in the range between $6.74-8.40 \mathrm{ppm}$. Signals of the characteristic amino group (7.06-7.18 ppm), $N, N$-dimethylamino group ( $\sim 3.18 \mathrm{ppm}), t$-butyl $(\sim 1.33 \mathrm{ppm})$ and methoxy $(\sim 3.86 \mathrm{ppm})$ were also observed. In the ${ }^{13} \mathrm{C}-\mathrm{NMR}$ spectra the characteristic peaks from 1,3,4-thiadiazole carbon atoms C-2 and C-5 were observed at 164-166 ppm and 178-181 ppm, respectively. Signals due to methoxy group ( $\sim 55.5 \mathrm{ppm}), t$-butyl group (30.8-34.8 ppm) and $\mathrm{N}, \mathrm{N}$-dimethylamino group (40.0-40.2 ppm) were observed upfield in the spectra. The formation of azo dyes $\mathbf{4 a - e}, \mathbf{5 a - e}, \mathbf{6 a}-\mathbf{e}$ was further shown by HRMS and elemental analyses.

The IR spectra of all prepared dyes were recorded from 4000 and $650 \mathrm{~cm}^{-1}$. For the dyes $4 a-\mathbf{e}$, two bands, respectively at $3400-3310 \mathrm{~cm}^{-1}$ and $3201-3190 \mathrm{~cm}^{-1}$, were visible, which were attributed to the presence of a free amino group. Such bands were not observed in the case of derivatives $5 \mathbf{a}-\mathbf{e}$, representing a group of tertiary amines. In series $6 \mathbf{a}-\mathbf{e}$, a broad band appeared from $3500-3100 \mathrm{~cm}^{-1}$, which confirms the presence of a hydroxyl group. All dyes showed a weak band at $1505-1525 \mathrm{~cm}^{-1}$ for an azo group $(\mathrm{N}=\mathrm{N})$.

The UV-Vis spectra of three series of 2-arylazo-5-aryl-1,3,4-thiadiazole dyes (4a-e, 5a-e, $\mathbf{6 a}-\mathbf{e})$ measured in $\mathrm{MeOH}$ exhibit several (four in most cases) absorption maxima (Figure 1, Table 1). The same is observed for calculated spectra (Figure 1, Table 1) which are in good comparison with those measured. All maxima result from multiple different transitions and include both $\mathrm{n} \rightarrow \pi^{*}$ and $\pi \rightarrow \pi^{*}$ transitions. For series $\mathbf{5}$ and $\mathbf{6}$ with compounds possessing a t-butyl group, additionally the $\sigma \rightarrow \pi^{*}$ transitions are observed. Due to complexity of electronic transition creating each absorption maximum, there is no one evident dependence between the substituents and absorption maximum position/absorption coefficient (Figure S1). Nevertheless, some dependences exist within groups with one kind of $R$ or $G$ substituent. The change of the $G$ substituent causes the red shift of the most intense absorption maximum (appearing in the visible regions of 490-507 nm for 4a-e, 515-530 nm for $5 \mathbf{a}-\mathbf{e}$ and $405-415 \mathrm{~nm}$ for $\mathbf{6 a}-\mathbf{e}$ ) in order of $\mathrm{G}$ substituents: $\mathrm{OH}, \mathrm{NH}_{2}, \mathrm{NMe}_{2}$. This sequence is in 
agreement with electron donating properties of the studied substituents. These red shifts are well reproduced in calculated spectra (Table 1). For the compounds with amino substituents $\left(\mathrm{G}=\mathrm{NH}_{2}\right.$, $\mathrm{NMe}_{2}$ ) this maximum is the most red-shifting for a compound possessing a nitro group (Table 1). For the compounds with hydroxy group $(\mathrm{G}=\mathrm{OH})$ the red shift forced by the presence of a nitro group (6c) is between some other red shifted compounds, and it is smaller than that shift observed for the compound $\mathbf{6 b}$. This effect is also reflected in the calculated spectra (Table 1 ). The simultaneous presence of a hydroxy group $(\mathrm{G}=\mathrm{OH})$ and methoxy one $(\mathrm{R}=\mathrm{MeO})$ in $\mathbf{6} \mathbf{b}$ is an explanation of this phenomenon. For each series, the methoxy moiety induces red-shift effect (toward most of the compounds), but for amino substituents $\mathrm{G}=\mathrm{NH}_{2}, \mathrm{NMe}_{2}$ it was smaller than for their hydroxy counterpart $\mathrm{G}=\mathrm{OH}$ (influence of this group could only be noticed for calculated spectra). Increase of the red shift for stronger electron donating EDG substituents $\left(\mathrm{G}=\mathrm{NMe}_{2}\right.$ and $\left.\mathrm{NH}_{2}\right)$ is larger than caused by methoxy moiety and overrule strong electron withdrawing properties of nitro substituent. In case of the weaker EDG substituent $(\mathrm{G}=\mathrm{OH})$ with electron donating properties close to the methoxy substituent, the electron withdrawing properties of nitro substituent dominate at some point, and cause above described difference in red shifts. For each compound, the most intense (global) maximum is attributed to HOMO-LUMO $(\mathrm{H} \rightarrow \mathrm{L})$ transitions (Table 1, Supplementary Materials, Figures S2-S4). For compounds possessing the nitro substituent these experimentally observed absorption maxima result also from other than $\mathrm{H} \rightarrow \mathrm{L}$ transitions, possessing relatively large oscillator strengths (Table 1, Figures S2-S4). In all cases, these transitions do not engage the antibonding orbitals of the nitro group (Table 1). For the second most intense absorption maximum (experimentally observed at lower wavelengths), the changes of its shift between the corresponding compounds (e.g., 4a vs. 5a vs. 6a) are not as high as those observed for the most intense maxima. Those maxima appear in the ultraviolet regions of 237-267 $\mathrm{nm}$ for 4a-e, 243-256 nm for 5a-e and 243-260 $\mathrm{nm}$ for 6a-e and they results from multiple $\pi \rightarrow \pi^{*}$ and $\mathrm{n} \rightarrow \pi^{*}$ transitions involving antibonding orbitals of all substituents (i.e., $\mathrm{NH}_{2}, \mathrm{NMe}_{2}, \mathrm{OH}_{\text {, }}$ $\mathrm{MeO}, \mathrm{NO}_{2}$ and $\mathrm{Br}$, Table 1). The experimental and calculated spectra show some minor differences. For compounds with amino groups $\left(\mathrm{G}=\mathrm{NH}_{2}, \mathrm{NMe}_{2}\right)$, the calculated spectra do not contain absorption maxima observed experimentally in the range of 284-299 $\mathrm{nm}$. This may result from the interaction of compound molecules with the solvent (i.e., formation of specific hydrogen bonds) defectively reproduced in continuous model of solvation.

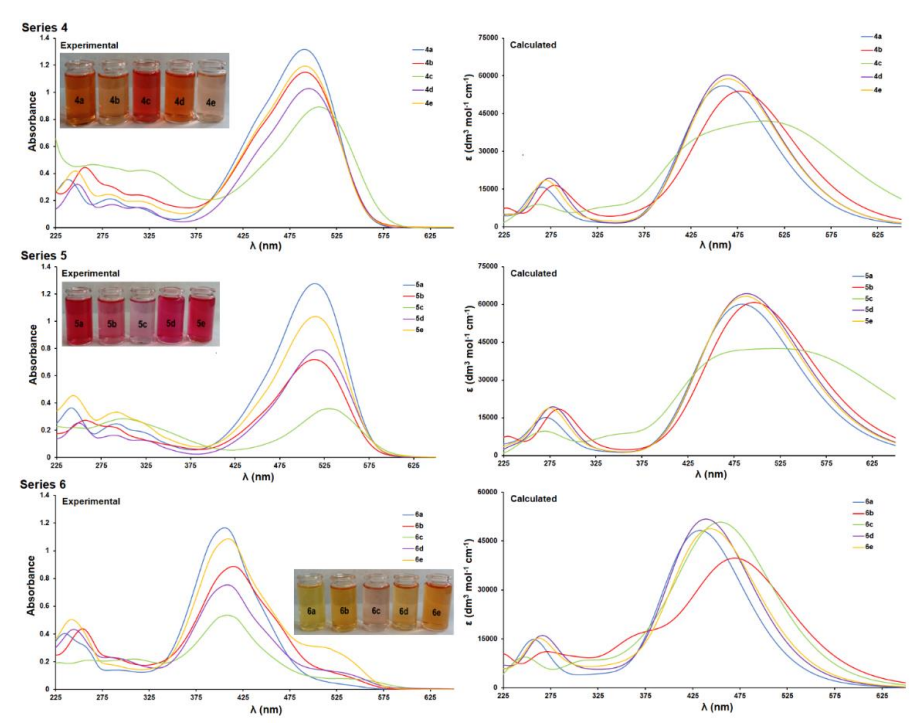

Figure 1. UV-Vis absorption spectra of the studied azo dyes in $\mathrm{MeOH}$ at a concentration of $4.0 \times 10^{-5}-\mathrm{mol} / \mathrm{L}$ at room temperature: (Series 4) Absorption spectra of azo dyes 4a-e containing 4-aminophenylazo group; (Series 5) absorption spectra of azo dyes 5a-e containing 4-(N,N-dimethylamino)phenylazo group; (Series 6) absorption spectra of azo dyes 6a-e containing 4-hydroxyphenylazo group. Respective calculated spectra are shown as well. 
Table 1. Most important electronic transitions. H letter indicates Highest Occupied Molecular Orbital HOMO, L indicates Lowest Unoccupied Molecular Orbital LUMO and +/- (number) represent subsequent orbitals above HOMO and LUMO, respectively. The logarithm of molar absorption coefficients log $\varepsilon$ and oscillator strengths are given in parenthesis under the wavelengths, respectively for experimental and calculated maxima. The letters a-e stand for the particular compound in a given series $(4,5$ or 6$)$.

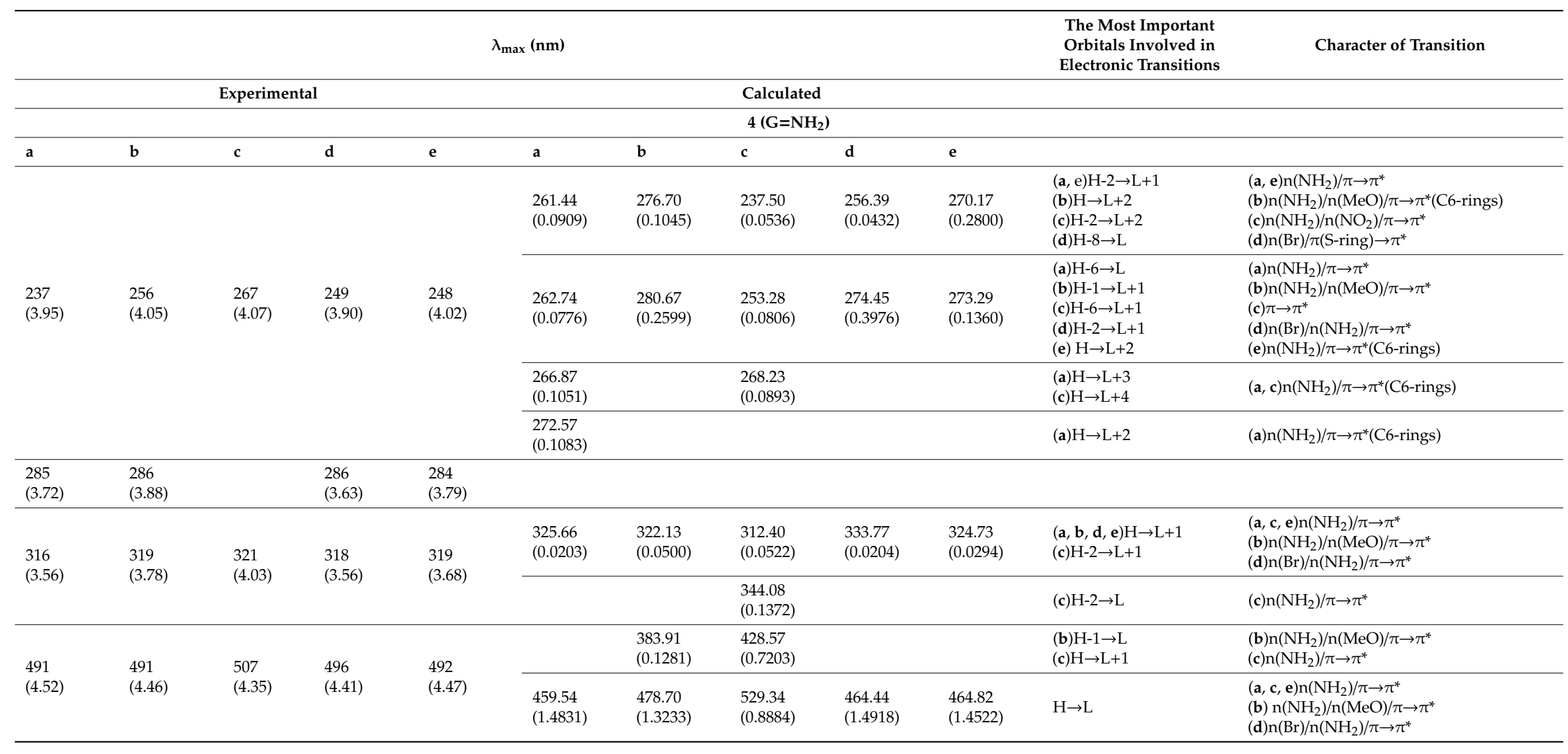


Table 1. Cont.

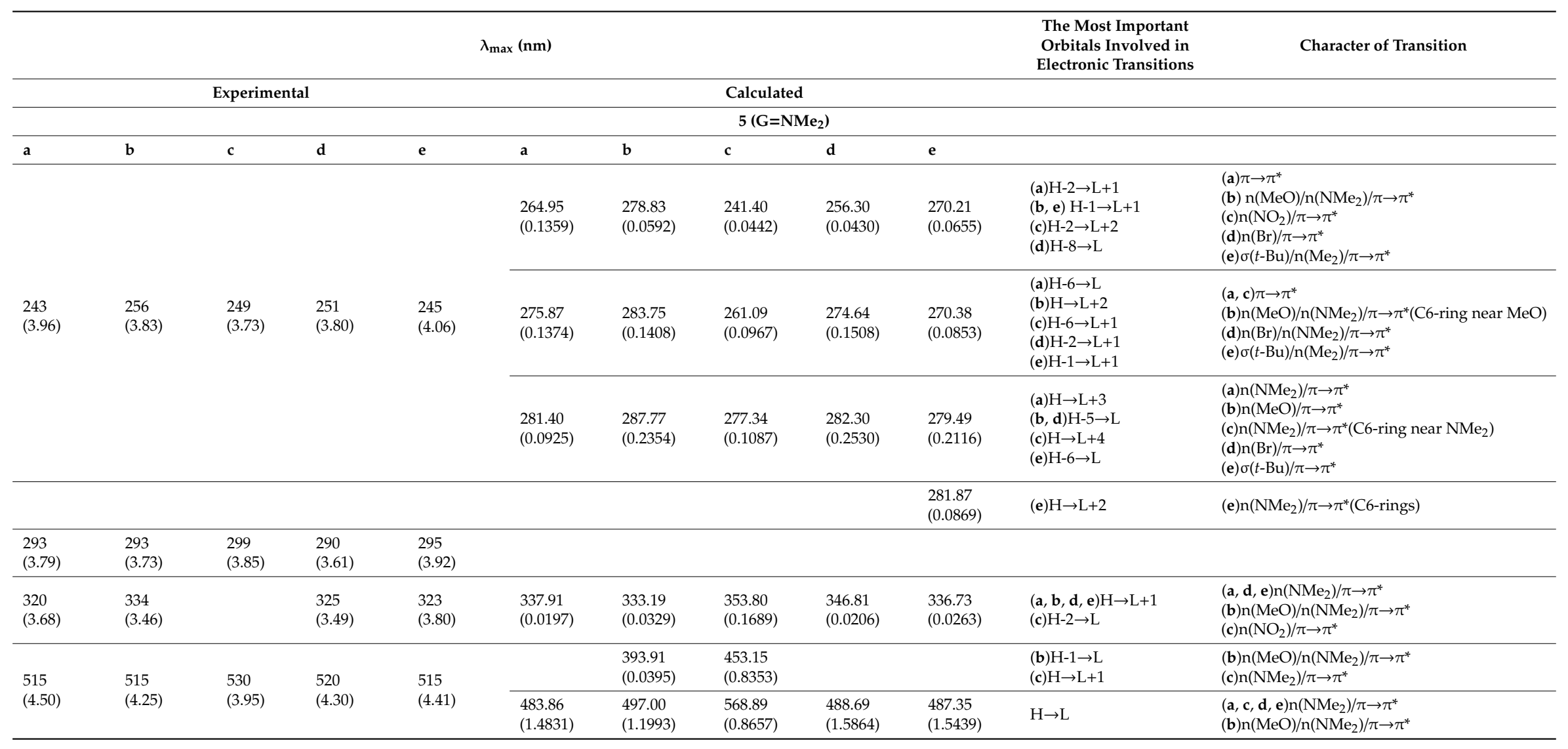


Table 1. Cont.

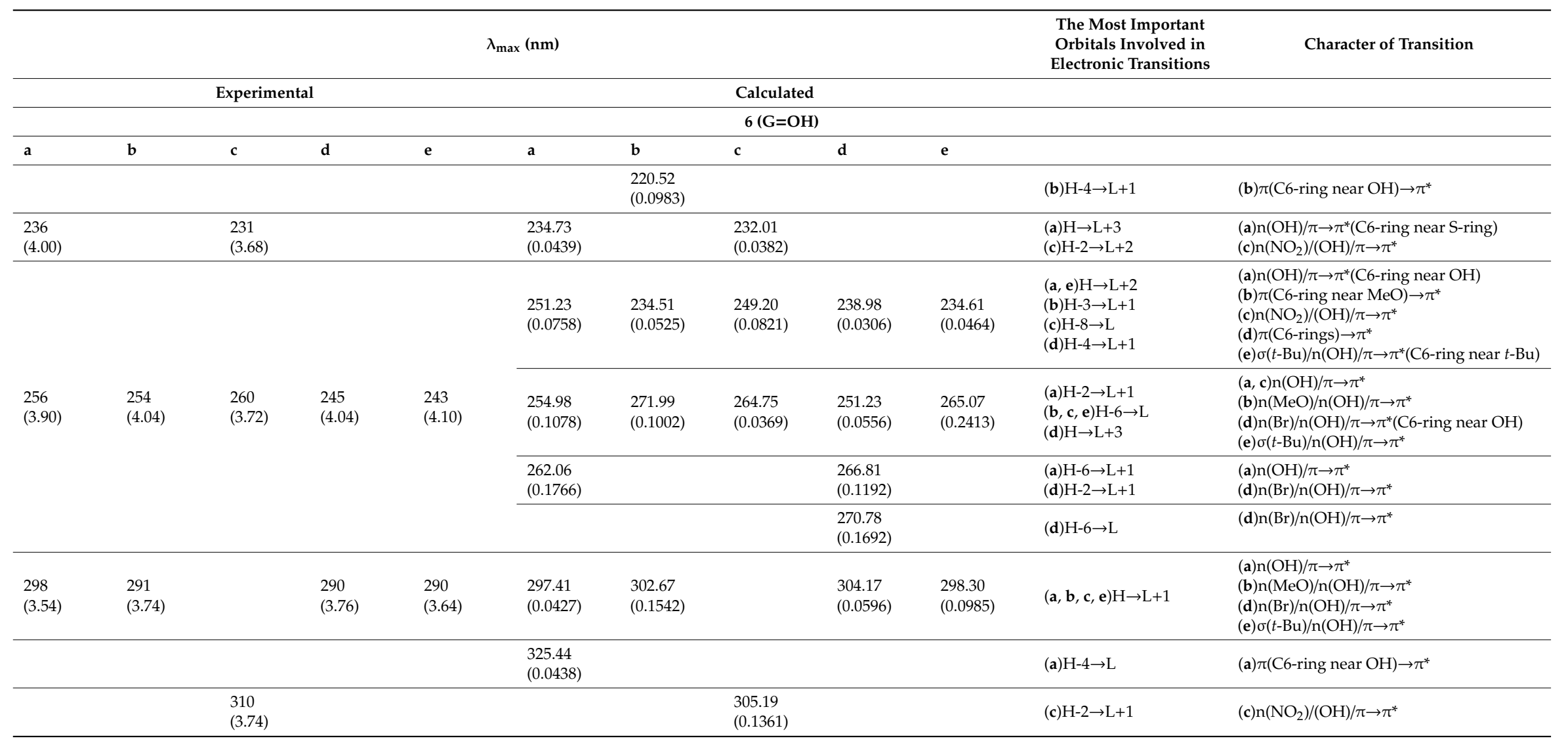


Table 1. Cont.

\begin{tabular}{|c|c|c|c|c|c|c|c|c|c|c|c|}
\hline \multicolumn{10}{|c|}{$\lambda_{\max }(\mathrm{nm})$} & \multirow[t]{2}{*}{$\begin{array}{l}\text { The Most Important } \\
\text { Orbitals Involved in } \\
\text { Electronic Transitions }\end{array}$} & \multirow[t]{2}{*}{ Character of Transition } \\
\hline & & Experim & & & & & Calcula & & & & \\
\hline \multirow{3}{*}{$\begin{array}{l}405 \\
(4.46)\end{array}$} & \multirow{3}{*}{$\begin{array}{l}415 \\
(4.35)\end{array}$} & \multirow{3}{*}{$\begin{array}{l}410 \\
(4.13)\end{array}$} & \multirow{3}{*}{$\begin{array}{l}409 \\
(4.28)\end{array}$} & \multirow{3}{*}{$\begin{array}{l}409 \\
(3.96)\end{array}$} & & & $\begin{array}{l}341.08 \\
(0.0630)\end{array}$ & & & $($ c) $\mathrm{H}-3 \rightarrow \mathrm{L}$ & (c) $\pi($ C6-ring near $\mathrm{OH}) \rightarrow \pi^{*}$ \\
\hline & & & & & $\begin{array}{l}345.44 \\
(0.0461)\end{array}$ & $\begin{array}{l}370.43 \\
(0.3618)\end{array}$ & $\begin{array}{l}385.35 \\
(0.2630)\end{array}$ & $\begin{array}{l}355.56 \\
(0.0770)\end{array}$ & $\begin{array}{l}355.42 \\
(0.1288)\end{array}$ & $\begin{array}{l}(\mathbf{a}, \mathbf{d}, \mathbf{e}) \mathrm{H}-2 \rightarrow \mathrm{L} \\
(\mathbf{b}) \mathrm{H}-1 \rightarrow \mathrm{L} \\
(\mathbf{c}) \mathrm{H}-1 \rightarrow \mathrm{L}+1\end{array}$ & $\begin{array}{l}(\mathbf{a}, \mathbf{c}) \mathrm{n}(\mathrm{OH}) / \pi \rightarrow \pi^{*} \\
\text { (b) } \mathrm{n}(\mathrm{MeO}) / \mathrm{n}(\mathrm{OH}) / \pi \rightarrow \pi^{*} \\
\left(\text { d) } \mathrm{n}(\mathrm{Br}) / \mathrm{n}(\mathrm{OH}) / \pi \rightarrow \pi^{*}\right. \\
\text { (e) } \sigma(t-\mathrm{Bu}) / \mathrm{n}(\mathrm{OH}) / \pi \rightarrow \pi^{*}\end{array}$ \\
\hline & & & & & $\begin{array}{l}432.77 \\
(1.1904)\end{array}$ & $\begin{array}{l}471.46 \\
(0.9677)\end{array}$ & $\begin{array}{l}458.02 \\
(1.1983)\end{array}$ & $\begin{array}{l}439.27 \\
(1.2728)\end{array}$ & $\begin{array}{l}444.00 \\
(1.1983)\end{array}$ & $\mathrm{H} \rightarrow \mathrm{L}$ & $\begin{array}{l}(\mathrm{a}, \mathrm{c}) \mathrm{n}(\mathrm{OH}) / \pi \rightarrow \pi^{*} \\
\text { (b)n(MeO)/n(OH)/ } \mathrm{n} \rightarrow \pi^{*} \\
\left(\text { d) } \mathrm{n}(\mathrm{Br}) / \mathrm{n}(\mathrm{OH}) / \pi \rightarrow \pi^{*}\right. \\
\left(\text { e) } \sigma(t-\mathrm{Bu}) / \mathrm{n}(\mathrm{OH}) / \pi \rightarrow \pi^{*}\right.\end{array}$ \\
\hline
\end{tabular}

Used abbreviations: $\mathrm{n} —$ non-bonding orbital; S-ring—-thiadiazole ring; C6-ring—benzene ring; *—antibonding orbital. 


\subsection{Molecular Structure}

The structure of one of the obtained azo dyes was confirmed by X-ray crystal structure analysis (CCDC1946289). All atoms of the studied 2-[4-(N,N-dimethylamino)phenylazo]-5-(4-methoxyphenyl) -1,3,4-thiadiazole (5b) occupied general positions (Figure 2).

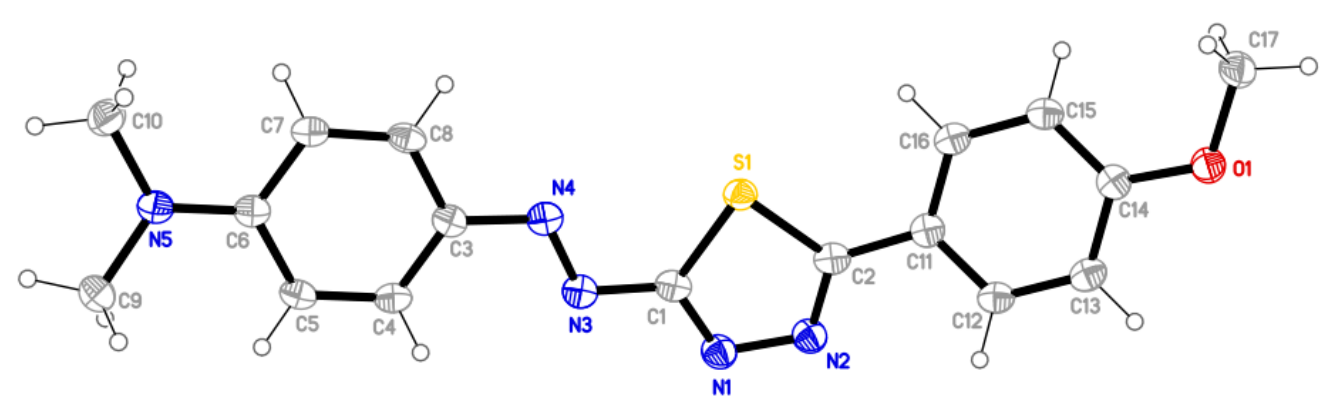

Figure 2. Molecular structure of compound $5 \mathbf{b}$ plotted with $50 \%$ probability of displacement ellipsoids. Hydrogen atoms are drawn as spheres with arbitrary radii.

The five- and six- membered rings were practically planar (the largest deviating atom C2, C7, C14 stuck out $0.0060(8), 0.0079(9), 0.0073(9) \AA$ from the weighted least squares plane containing the respective atom), but the whole molecule is considerably bent. The benzene rings containing C3 and C11 atoms were inclined at $10.11(7)$ and $24.90(6)^{\circ}$ to the central 1,3,4-thiadiazole ring, respectively and mutually at $26.85(6)^{\circ}$. The $N, N$-dimethylamino group was inclined at $11.53(14)^{\circ}$ to the neighboring benzene ring, which is a larger value than is typically observed for similar systems $\left(4.6 \%-5.8^{\circ}\right)$ [30]. However, it still falls within the range of $2.3 \%-18.8^{\circ}$ (the angle values of median population). The C-S bonds (Table 2) were shorter than typical single C-S bonds (i.e., a mean value of $1.819 \AA$ for a bond between an $\mathrm{sp}^{3}$ carbon atom and a divalent sulfur) and similar to the values observed for slightly delocalized systems containing $\mathrm{sp}^{2}$ carbon atoms (i.e., a mean value of $1.741 \AA$ ) [31]. A similar effect exists for an $\mathrm{N}-\mathrm{N}$ bond (a formal bond length of $1.454 \AA$ ) and opposite effects were observed for slightly longer $C=N$ bonds (Table 2) and double $\mathrm{C}=\mathrm{N}$ bonds (i.e., a mean value of $1.279 \AA$ [32]). Combined, these effects demonstrate small, but observable delocalization of electron density within the 1,3,4-thiadiazole ring. The azo N=N bond (Table 2) shows a transitional character between a well-localized and a completely delocalized system (mean values of 1.245 and $1.304 \AA$ ) [33]. This, along with the shortening of the neighboring $\mathrm{C}-\mathrm{N}$ bonds, also demonstrates the considerable degree of delocalization of electron density within the $\mathrm{C}-\mathrm{N}=\mathrm{N}-\mathrm{C}$ moiety. Due to the absence of classical hydrogen bond donors, the studied compounds are connected only by weak $\mathrm{C}-\mathrm{H} \bullet \bullet \bullet \mathrm{A}$ non-classic hydrogen bonds (where A denotes the following acceptors: N, O, S and $\pi$ electrons) [34] and $\pi \bullet \bullet \bullet \pi$ stacking interactions (Table 3, Table 4) [35].

Table 2. Selected structural data of studied compound $\mathbf{5 b}$.

\begin{tabular}{llllll}
\hline $\mathbf{i}-\mathbf{j}$ & $\mathbf{d}_{\mathbf{i j}}[\AA \mathbf{\AA}]$ & $\mathbf{i}-\mathbf{j}-\mathbf{k}$ & $\alpha_{\mathbf{i j k}}\left[^{\circ}\right]$ & $\mathbf{i}-\mathbf{j}-\mathbf{k}$ & $\alpha_{\mathbf{i j k}}\left[^{\circ}\right]$ \\
\hline S1-C1 & $1.7462(14)$ & C1-S1-C2 & $86.22(7)$ & C2-C11-C16 & $122.25(13)$ \\
S1-C2 & $1.7366(14)$ & S1-C2-N2 & $114.29(11)$ & C5-C6-N5 & $121.16(12)$ \\
C1-N1 & $1.3092(18)$ & C2-N2-N1 & $112.80(12)$ & C7-C6-N5 & $121.27(12)$ \\
C2-N2 & $1.3124(18)$ & N2-N1-C1 & $112.25(12)$ & C6-N5-C9 & $120.76(12)$ \\
N1-N2 & $1.3757(17)$ & N1-C1-S1 & $114.42(11)$ & C6-N5-C10 & $120.34(12)$ \\
C1-N3 & $1.3821(18)$ & N1-C1-N3 & $120.62(13)$ & C9-N5-C10 & $118.16(12)$ \\
N3-N4 & $1.2907(16)$ & S1-C1-N3 & $124.91(10)$ & C13-C14-O1 & $115.86(12)$ \\
N4-C3 & $1.3851(18)$ & C1-N3-N4 & $111.67(11)$ & C15-C14-O1 & $124.38(13)$ \\
C2-C11 & $1.4651(19)$ & N3-N4-C3 & $115.29(11)$ & C14-O1-C17 & $117.14(11)$ \\
N5-C6 & $1.3520(18)$ & N4-C3-C4 & $125.47(12)$ & & \\
N5-C9 & $1.4635(18)$ & N4-C3-C8 & $116.30(12)$ & & \\
N5-C10 & $1.4606(18)$ & S1-C2-C11 & $122.98(10)$ & & \\
O1-C14 & $1.3610(17)$ & N2-C2-C11 & $122.55(13)$ & & \\
O1-C17 & $1.4346(17)$ & C2-C11-C12 & $118.81(13)$ & & \\
\hline
\end{tabular}


Table 3. Non-classic hydrogen bonds and the first level graph motifs in the studied compound. $\mathrm{Cg}(\mathrm{C} 3)$ indicates centroid of ring containing $\mathrm{C} 3$ atom.

\begin{tabular}{|c|c|c|c|c|c|}
\hline $\mathrm{D}-\mathrm{H} \bullet \bullet \bullet A$ & $\mathrm{~d}(\mathrm{D}-\mathrm{H})[\AA]$ & $\mathrm{d}(\mathrm{H} \bullet \bullet \bullet \mathrm{A})[\AA]$ & $\mathrm{d}(\mathrm{D} \bullet \bullet \bullet \mathrm{A})[\AA]$ & $<$ (DHA) $\left[{ }^{\circ}\right]$ & $G_{d}^{a}(n)$ \\
\hline $\mathrm{C} 9-\mathrm{H} 9 \mathrm{~A} \bullet \bullet \bullet N 1$ i & 0.98 & 2.58 & $3.5351(1)$ & 165.4 & $\mathrm{R}_{2}^{2}(22)$ \\
\hline $\mathrm{C} 10-\mathrm{H} 10 \mathrm{~B} \bullet \bullet \bullet \mathrm{O} 1$ ii & 0.98 & 2.54 & $3.5031(1)$ & 166.3 & $\mathrm{C}(17)$ \\
\hline $\mathrm{C} 16-\mathrm{H} 16 \bullet \bullet \bullet \mathrm{S} 1$ & 0.95 & 2.86 & $3.2088(1)$ & 102.7 & $S(5)$ \\
\hline $\mathrm{C} 7-\mathrm{H} 7 \bullet \bullet \bullet \mathrm{Cg}(\mathrm{C} 3)^{\text {iii }}$ & 0.95 & 2.97 & $3.8190(1)$ & 148.8 & $C(2)$ \\
\hline
\end{tabular}

Symmetry transformations used to generate equivalent atoms: (i) $-\mathrm{x}+1,-\mathrm{y}+1,-\mathrm{z}-2$; (ii) $\mathrm{x}+1, \mathrm{y}, \mathrm{z}$; (iii) $\mathrm{x},-\mathrm{y}+1.5, \mathrm{z}-0.5$.

The unitary graph set is composed of $\mathrm{R}_{2}{ }^{2}(22) \mathrm{C}(17) \mathrm{S}(5) \mathrm{C}(2)$ motifs of the lowest degree. The ring motif assembles the molecules into supramolecular dimers (Figure 3), and the $C(17)$ chain motif extends these dimers to a supramolecular ribbon extending along the crystallographic axis (Figure 4). This ribbon is constructed from alternating $\mathrm{R}_{2}{ }^{2}(22) \mathrm{R}_{4}{ }^{4}(26)$ ring motifs of a binary graph set of the lowest degree. The neighboring ribbons are interconnected by $\mathrm{C}-\mathrm{H} \bullet \bullet \bullet \pi$ and $\pi \bullet \bullet \bullet \pi$ interactions (Table 3, Table 4) and form a three-dimensional network assembled by non-covalent interactions.

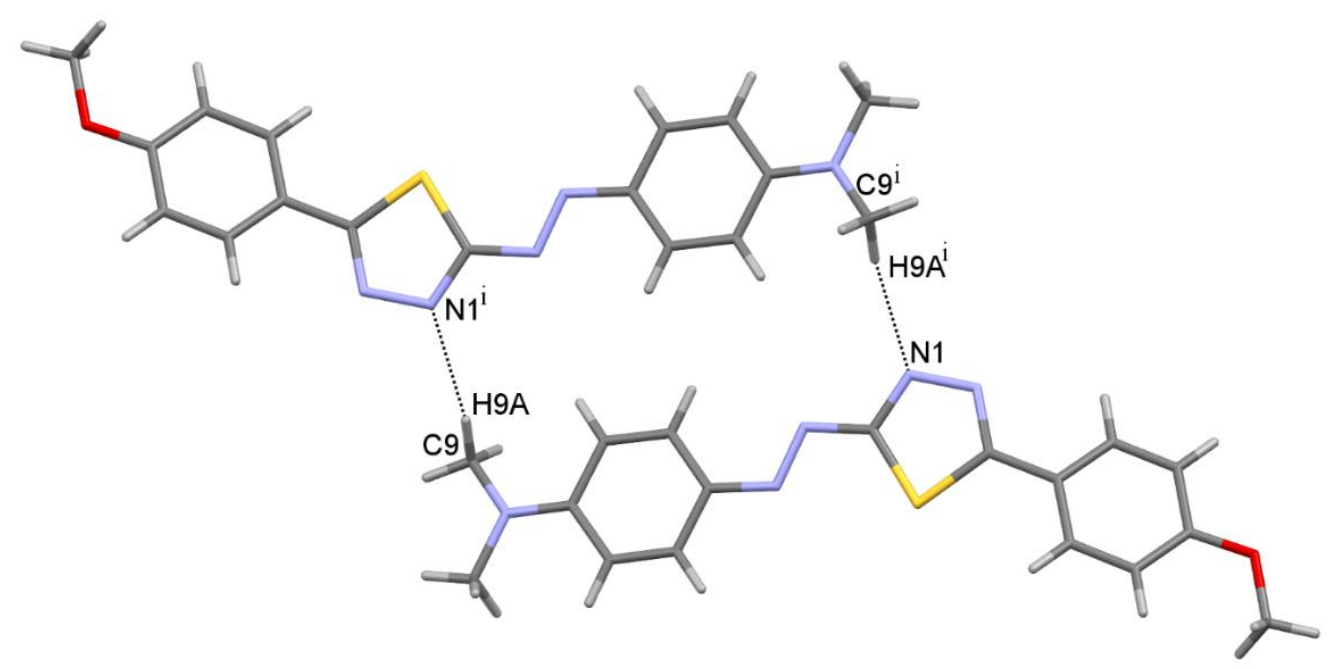

Figure 3. Supramolecular dimers forming a $\mathrm{R}_{2}{ }^{2}(22)$ motif of a unitary graph set. Symmetry codes as in Table 3. Non-classic hydrogen bonds are indicated by dotted lines.

Table 4. Interactions in the studied compound. Each ring is indicated by one atom, which belongs solely to this ring. $\alpha$ is a dihedral angle between planes I and J, $\beta$ is an angle between $\mathrm{Cg}(\mathrm{I})-\mathrm{Cg}(\mathrm{J})$ vector and normal to plane I and $d_{p}$ is the perpendicular distance of $C g(I)$ on ring J plane.

\begin{tabular}{lllll}
\hline $\mathbf{R}(\mathbf{I}) \bullet \bullet \bullet \mathbf{R}(\mathbf{J})$ & $\mathbf{d}(\mathbf{C g} \bullet \bullet \cdot \mathbf{C g})[\AA ⿻$ & $\left.\boldsymbol{\alpha}^{\circ}{ }^{\circ}\right]$ & $\boldsymbol{\beta}\left[^{\circ}\right]$ & $\mathbf{d}_{\mathbf{p}}[\AA ⿻$ \\
\hline $\mathrm{C} 3 \bullet \bullet \bullet C 3^{\text {iv }}$ & $3.6217(1)$ & 0 & 15.5 & 3.4908 \\
$\mathrm{C} 11 \bullet \bullet \bullet 11^{\mathrm{v}}$ & $3.5355(1)$ & 0 & 22.3 & 3.2703 \\
\hline
\end{tabular}

Symmetry transformations used to generate equivalent atoms: (iv) $-\mathrm{x}+1,-\mathrm{y}+1$ $-\mathrm{z}+1 ;(\mathrm{v})-\mathrm{x},-\mathrm{y}+1,-\mathrm{z}+1$. 


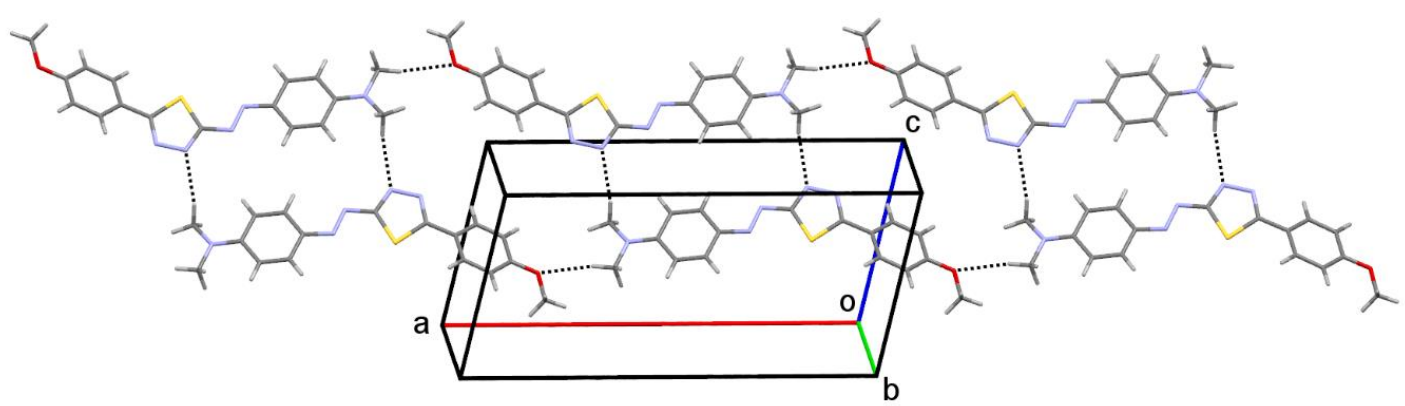

Figure 4. Part of molecular packing showing a supramolecular ribbon extending along the crystallographic axis. Hydrogen bonds indicated by dotted lines.

\section{Experimental}

\subsection{General Information}

All reagents were purchased from commercial sources and used without further purification. Melting points were measured on a Stuart SMP3 melting point apparatus. The ${ }^{1} \mathrm{H}-\mathrm{NMR}$ and ${ }^{13} \mathrm{C}-\mathrm{NMR}$ spectra were recorded on an Agilent 400-NMR spectrometer in DMSO- $d_{6}$ solution using TMS as the internal standard. FT-IR spectra were recorded between 4000 and $650 \mathrm{~cm}^{-1}$ using a FT-IR Nicolet 6700 apparatus with a Smart iTR accessory. UV-Vis spectra were recorded at room temperature in $\mathrm{MeOH}$ solutions $\left(\mathrm{c}=4.0 \times 10^{-5} \mathrm{~mol} / \mathrm{L}\right)$ on a Jasco V-660 spectrophotometer. High-resolution mass spectra were recorded on a Waters ACQUITY UPLC/Xevo G2QT instrument. Thin-layer chromatography was performed on silica gel $60 \mathrm{~F}_{254}$ (Merck) TLC plates using $\mathrm{CHCl}_{3} / \mathrm{EtOAc}(5: 1 \mathrm{v} / \mathrm{v})$ as the mobile phase. Elemental analyses were performed with a VarioEL analyzer. The excited states of the obtained compounds were calculated using TD-DFT method. All calculations (including geometry optimization) were performed utilizing Gaussian09 rev. D.01 [36] with B3LYP functional and employing $6.31 \mathrm{~g}++(2 \mathrm{~d}, 2 \mathrm{p})$ basis set. The geometry of all compounds was optimized and during this calculation D3 version of Grimme's dispersion with Becke-Johnson damping [37] was used. In both, the optimization process and TD-DFT calculations, the polarizable continuum model [38] was used to include overall solvation effects (with methanol selected as a solvent). The assignment of the calculated excited states to the observed experimental maxima was based on the comparison of excitation energies and the oscillator strengths/intensities of the corresponding maxima. The analysis of the character of respective orbital excitations was based on orbital contour plots.

\subsection{Synthesis and Characterization}

\subsubsection{General Procedure for the Synthesis of 2-Benzoylhydrazinecarbothioamide Derivatives (2a-e)}

A carboxylic acid (1a-e, $0.10 \mathrm{~mol})$ and thionyl chloride $\mathrm{SOCl}_{2}(22 \mathrm{~mL}, 0.30 \mathrm{~mol})$ were refluxed in dry toluene $(10 \mathrm{~mL})$ until the acid was fully consumed (TLC; 5-15 h). After cooling, the mixture was concentrated on a rotary evaporator, washed with additional dry toluene $(10 \mathrm{~mL})$ and concentrated again. The crude acid chloride was then dissolved in $50 \mathrm{~mL}$ of dry toluene and added dropwise to a mixture of thiosemicarbazide $(9.11 \mathrm{~g}, 0.10 \mathrm{~mol}), \mathrm{NaHCO}_{3}(8.40 \mathrm{~g}, 0.10 \mathrm{~mol})$ and $\mathrm{H}_{2} \mathrm{O}(150 \mathrm{~mL})$. The whole solution was agitated at room temperature overnight. The precipitated solid was filtered off, dried in air and recrystallized from a mixture of $\mathrm{EtOH}-\mathrm{H}_{2} \mathrm{O}$ to obtain pure 2-benzoylhydrazinecarbothioamide derivatives (2a-e).

2-Benzoylhydrazinecarbothioamide (2a). The product was obtained as a white solid (8.60 g, 44\%); mp 197-198 ${ }^{\circ} \mathrm{C}\left(196-198^{\circ} \mathrm{C}[39]\right)$.

2-(4-Methoxybenzoylhydrazinecarbothioamide (2b). The product was obtained as a white solid (15.32 g, 68\%); mp $225-227^{\circ} \mathrm{C}\left(226^{\circ} \mathrm{C}[40]\right)$. 
2-(4-Nitrobenzoylhydrazinecarbothioamide (2c). The product was obtained as a yellow solid (18.02 g, $75 \%) ; \mathrm{mp} 212-214{ }^{\circ} \mathrm{C}\left(214^{\circ} \mathrm{C}[41]\right)$.

2-(4-Bromobenzoylhydrazinecarbothioamide (2d). The product was obtained as a white solid (16.72 g, 75\%); mp 216-218 ${ }^{\circ} \mathrm{C} .{ }^{1} \mathrm{H}-\mathrm{NMR}\left(400 \mathrm{MHz}, \mathrm{DMSO}-\mathrm{d}_{6}\right): \delta 7.68-7.72(\mathrm{~m}, 3 \mathrm{H}, \mathrm{Ar}: \mathrm{H}-3, \mathrm{H}-5, \mathrm{NH})$, 7.82-7.88 (m, 3H, Ar: H-2, H-6, NH), 9.34 (s, 1H, NH), 10.45 (s, 1H, NH); ${ }^{13} \mathrm{C}-\mathrm{NMR}(100 \mathrm{MHz}$, DMSO-d $\left.{ }_{6}\right): \delta 125.5,129.5,129.9,131.1,131.7,164.9(\mathrm{C}=\mathrm{O}), 182.0(\mathrm{C}=\mathrm{S})$; Anal. Calcd for $\mathrm{C}_{8} \mathrm{H}_{8} \mathrm{BrN}_{3} \mathrm{OS}$ : C, 35.05; H, 2.94; N, 15.33. Found: C, 34.95; H, 2.89; N, 15.40 .

2-(4-t-Butylbenzoylhydrazinecarbothioamide (2e). The product was obtained as a beige solid (12.06 $\mathrm{g}$, $48 \%)$ mp 210-211 ${ }^{\circ} \mathrm{C} .{ }^{1} \mathrm{H}-\mathrm{NMR}\left(400 \mathrm{MHz}, \mathrm{DMSO}-\mathrm{d}_{6}\right): \delta 1.33\left(\mathrm{~s}, 9 \mathrm{H}, \mathrm{C}\left(\mathrm{CH}_{3}\right)_{3}\right), 7.48(\mathrm{~d}, 2 \mathrm{H}, J=8.4 \mathrm{~Hz}$, Ar: H-3, H-5), 7.52-7.60 (m, 2H, NH 2$), 7.84(\mathrm{~d}, 2 \mathrm{H}, J=8.4 \mathrm{~Hz}$ Ar: H-2, H-6), 9.31 (s, 1H, NH), 10.39 (s, 1H, NH); ${ }^{13} \mathrm{C}-\mathrm{NMR}\left(100 \mathrm{MHz}, \mathrm{DMSO}-\mathrm{d}_{6}\right): \delta 30.8,34.8,124.9,126.1,128.3,154.6,165.6(\mathrm{C}=\mathrm{O})$, $182.0(\mathrm{C}=\mathrm{S})$; Anal. Calcd for $\mathrm{C}_{12} \mathrm{H}_{17} \mathrm{~N}_{3} \mathrm{OS}$ : $\mathrm{C}, 57.34 ; \mathrm{H}, 6.82 ; \mathrm{N}, 16.72$. Found: $\mathrm{C}, 57.21 ; \mathrm{H}, 6.88 ; \mathrm{N}, 16.63$.

\subsubsection{General Procedure for the Synthesis of 2-Amino-1,3,4-thiadiazole Derivatives (3a-e)}

Derivatives of 2-benzoylhydrazinecarbothioamide $2 \mathbf{a}-\mathbf{e}(0.05 \mathrm{~mol})$ were dissolved in $50 \mathrm{~mL}$ of concentrated $\mathrm{H}_{2} \mathrm{SO}_{4}$ and agitated at room temperature overnight. Then, the mixture was alkalized with $25 \%$ ammonia and the precipitated product was filtered off, dried in air and recrystallized from a mixture of EtOH- $\mathrm{H}_{2} \mathrm{O}$ to yield the corresponding 2-amino-1,3,4-thiadiazoles 3a-e.

2-Amino-5-phenyl-1,3,4-thiadiazole (3a). The product was obtained as a white solid ( $3.89 \mathrm{~g}, 45 \%)$; $\mathrm{mp} 232-233^{\circ} \mathrm{C}\left(230^{\circ} \mathrm{C}[42]\right)$.

2-Amino-5-(4-methoxyphenyl)-1,3,4-thiadiazole (3b). The product was obtained as a white solid (3.42 g, 33\%); mp $184-185^{\circ} \mathrm{C}\left(185-187^{\circ} \mathrm{C}[43]\right)$.

2-Amino-5-(4-nitrophenyl)-1,3,4-thiadiazole (3c). The product was obtained as a yellow solid (8.33 $\mathrm{g}$, $75 \%) ; \mathrm{mp} 254-256^{\circ} \mathrm{C}\left(250-252{ }^{\circ} \mathrm{C}[44]\right)$.

2-Amino-5-(4-bromophenyl)-1,3,4-thiadiazole (3d). The product was obtained as a white solid (8.96 g, $70 \%) ; \mathrm{mp} 226^{\circ} \mathrm{C}\left(222-224{ }^{\circ} \mathrm{C}[41]\right)$.

2-Amino-5-(4-t-butylphenyl)-1,3,4-thiadiazole (3e). The product was obtained as a white solid $(4.78 \mathrm{~g}, 41 \%) ; \mathrm{mp} 251-253{ }^{\circ} \mathrm{C} .{ }^{1} \mathrm{H}-\mathrm{NMR}\left(400 \mathrm{MHz}, \mathrm{DMSO}-\mathrm{d}_{6}\right): \delta 1.29\left(\mathrm{~s}, 9 \mathrm{H}, \mathrm{C}\left(\mathrm{CH}_{3}\right)_{3}\right), 7.35(\mathrm{~s}, 2 \mathrm{H}$, $\left.\mathrm{NH}_{2}\right), 7.48$ (d, 2H, J = 8.4 Hz, Ar: H-3, H-5), 7.67 (d, 2H, $\left.J=8.4 \mathrm{~Hz}, \mathrm{Ar}: \mathrm{H}-2, \mathrm{H}-6\right) ;{ }^{13} \mathrm{C}-\mathrm{NMR}(100 \mathrm{MHz}$, DMSO-d $\mathrm{d}_{6}$ ): $\delta 30.8,34.5,125.8,126.0,128.3,152.2,156.3,168.1$; Anal. Calcd for $\mathrm{C}_{12} \mathrm{H}_{15} \mathrm{~N}_{3} \mathrm{~S}: \mathrm{C}, 61.77 ; \mathrm{H}$, 6.48; N, 18.01. Found: C, 61.70; H, 6.40; N, 18.12.

\subsubsection{General Procedure for the Synthesis of 2-(4-Aminophenylazo)-5-phenyl-1,3,4-thiadiazole} Derivatives (4a-e)

Sodium nitrite $(1.31 \mathrm{~g}, 0.019 \mathrm{~mol})$ was introduced portion wise into concentrated sulfuric acid $(20 \mathrm{~mL})$. The solution was heated to $50{ }^{\circ} \mathrm{C}$ in a water bath until complete dissolution and then rapidly cooled in an ice/salt bath to $0{ }^{\circ} \mathrm{C}$. In the meantime, the solution of the appropriate 2-amino-5-aryl-1,3,4-thiadiazole $3 a-\mathbf{e}(0.015 \mathrm{~mol})$ in glacial acetic acid $(30 \mathrm{~mL})$ and propionic acid $(15 \mathrm{~mL})$ was prepared and added dropwise to an agitated solution of sodium nitrite in concentrated sulfuric acid at $0-5{ }^{\circ} \mathrm{C}$. Then, the mixture was stirred for $24 \mathrm{~h}$, and excess nitrous acid was decomposed by the addition of urea. The resulting diazonium salt solution was slowly introduced into the mixture of aniline $(1.37 \mathrm{~mL}, 1.39 \mathrm{~g}, 0.015 \mathrm{~mol})$ in $15 \mathrm{~mL}$ of water at $0-5^{\circ} \mathrm{C}$. The colored mixture was stirred at room temperature for the next $24 \mathrm{~h}$ and finally neutralized with saturated sodium carbonate solution $(75 \mathrm{~mL})$. The solid was filtered off, washed twice with hot water $(2 \times 25 \mathrm{~mL})$ and dried in air. The crude product (4a-e) was purified by column chromatography on silica gel $\left(\mathrm{CHCl}_{3} / \mathrm{EtOAc}, 5: 1 \mathrm{v} / \mathrm{v}\right)$.

2-(4-Aminophenylazo)-5-phenyl-1,3,4-thiadiazole (4a). The product was obtained as a brown reddish solid (2.11 g, 51\%); mp 236-238 ${ }^{\circ} \mathrm{C} ; \mathrm{R}_{\mathrm{f}}\left(\mathrm{CHCl}_{3} / \mathrm{EtOAc}\right.$ 5:1 v/v) 0.18. ${ }^{1} \mathrm{H}-\mathrm{NMR}\left(400 \mathrm{MHz}, \mathrm{DMSO}-\mathrm{d}_{6}\right)$ : $\delta 6.75$ (d, 2H, $J=8.8 \mathrm{~Hz}, 2-\mathrm{Ar}: \mathrm{H}-3, \mathrm{H}-5), 7.13$ (s, 2H, NH 2 ), 7.57-7.59 (m, 3H, 5-Ar: H-3' , H-4' , H-5'), $7.77(\mathrm{~d}, 2 \mathrm{H}, J=8.8 \mathrm{~Hz}, 2-\mathrm{Ar}: \mathrm{H}-2, \mathrm{H}-6), 8.04\left(\mathrm{~d}, 2 \mathrm{H}, J=8.4 \mathrm{~Hz}, 5-\mathrm{Ar}: \mathrm{H}-2^{\prime}, \mathrm{H}-6^{\prime}\right) ;{ }^{13} \mathrm{C}-\mathrm{NMR}(100 \mathrm{MHz}$, DMSO-d ${ }_{6}$ ): $\delta 114.1,127.5,127.8,129.4,130.1,131.5,142.3,156.6,165.7,180.2$. IR (ATR) v: 3311, 1636, 
$1507 \mathrm{~cm}^{-1}$; HRMS calcd for $\left(\mathrm{C}_{14} \mathrm{H}_{11} \mathrm{~N}_{5} \mathrm{~S}+\mathrm{H}^{+}\right)$: 282.0813; found: 282.0818; Anal. Calcd for $\mathrm{C}_{14} \mathrm{H}_{11} \mathrm{~N}_{5} \mathrm{~S}$ : C, 59.77; H, 3.94; N, 24.89. Found: C, 59.83; H, 3.97; N, 24.93.

2-(4-Aminophenylazo)-5-(4-methoxyphenyl)-1,3,4-thiadiazole (4b). The product was obtained as a brown reddish solid $(2.47 \mathrm{~g}, 53 \%) ; \mathrm{mp} 269-270{ }^{\circ} \mathrm{C} ; \mathrm{R}_{\mathrm{f}}\left(\mathrm{CHCl}_{3} / \mathrm{EtOAc}, 5: 1 \mathrm{v} / \mathrm{v}\right) 0.16 .{ }^{1} \mathrm{H}-\mathrm{NMR}(400 \mathrm{MHz}$, DMSO- $\left.\mathrm{d}_{6}\right): \delta 3.86\left(\mathrm{~s}, 3 \mathrm{H}, \mathrm{OCH}_{3}\right), 6.74(\mathrm{~d}, 2 \mathrm{H}, J=8.8 \mathrm{~Hz}, 2-\mathrm{Ar}: \mathrm{H}-3, \mathrm{H}-5), 7.06\left(\mathrm{~s}, 2 \mathrm{H}, \mathrm{NH}_{2}\right), 7.11(\mathrm{~d}, 2 \mathrm{H}$, $\left.J=8.8 \mathrm{~Hz}, 5-\mathrm{Ar}: \mathrm{H}-3^{\prime}, \mathrm{H}^{\prime} 5^{\prime}\right), 7.75$ (d, 2H, $\left.J=8.8 \mathrm{~Hz}, 2-\mathrm{Ar}: \mathrm{H}-2, \mathrm{H}-6\right), 7.98$ (d, 2H, $J=8.8 \mathrm{~Hz}, 5-\mathrm{Ar}: \mathrm{H}-2^{\prime}$, H-6 $\left.{ }^{\prime}\right) ;{ }^{13}$ C-NMR (100 MHz, DMSO-d $\left.\mathrm{d}_{6}\right): \delta 55.5,114.1,114.8,122.6,127.6,129.2,142.3,156.3,161.8,165.6$, 179.5. IR (ATR) v: 3422, 3333, 1651, $1508 \mathrm{~cm}^{-1}$; HRMS calcd for $\left(\mathrm{C}_{15} \mathrm{H}_{13} \mathrm{~N}_{5} \mathrm{SO}+\mathrm{H}^{+}\right)$: 312.0919; found: 312.0912; Anal. Calcd for $\mathrm{C}_{15} \mathrm{H}_{13} \mathrm{~N}_{5} \mathrm{SO}$ : C, 57.86; $\mathrm{H}, 4.21 ; \mathrm{N}, 22.49$. Found: $\mathrm{C}, 57.73 ; \mathrm{H}, 4.24 ; \mathrm{N}, 22.43$.

2-(4-Aminophenylazo)-5-(4-nitrophenyl)-1,3,4-thiadiazole (4c). The product was obtained as a dark brown solid (3.42 g, 70\%); mp 176-178 ${ }^{\circ} \mathrm{C}\left(178-179{ }^{\circ} \mathrm{C}[24]\right) ; \mathrm{R}_{\mathrm{f}}\left(\mathrm{CHCl}_{3} / \mathrm{EtOAc}, 5: 1 \mathrm{v} / v\right)$ 0.23. IR (ATR) v: $3403,1637,1513 \mathrm{~cm}^{-1}$; Anal. Calcd for $\mathrm{C}_{14} \mathrm{H}_{10} \mathrm{~N}_{6} \mathrm{O}_{2} \mathrm{~S}: \mathrm{C}, 51.53 ; \mathrm{H}, 3.09 ; \mathrm{N}, 25.75$. Found: $\mathrm{C}, 51.47 ; \mathrm{H}$, $3.05 ; \mathrm{N}, 25.77$.

2-(4-Aminophenylazo)-5-(4-bromophenyl)-1,3,4-thiadiazole (4d). The product was obtained as a dark violet solid (3.67 g, 68\%); $\mathrm{mp} 261-263{ }^{\circ} \mathrm{C} ; \mathrm{R}_{\mathrm{f}}\left(\mathrm{CHCl}_{3} / \mathrm{EtOAc}, 3: 1 \mathrm{v} / \mathrm{v}\right) 0.23 .{ }^{1} \mathrm{H}-\mathrm{NMR}(400 \mathrm{MHz}$ DMSO-d 6 ): $\delta 6.75(\mathrm{~d}, 2 \mathrm{H}, J=9.2 \mathrm{~Hz}, 2-\mathrm{Ar}: \mathrm{H}-3, \mathrm{H}-5), 7.18$ (s, 2H, NH$\left.)_{2}\right), 7.75-7.78$ (m, 4H, 2-Ar, 5-Ar: H-2, H-6, $\left.\mathrm{H}-3^{\prime}, \mathrm{H}-5^{\prime}\right), 7.97$ (d, 2H, $\left.J=8.8 \mathrm{~Hz}, 5-\mathrm{Ar}: \mathrm{H}-2^{\prime}, \mathrm{H}-6^{\prime}\right) ;{ }^{13} \mathrm{C}-\mathrm{NMR}\left(100 \mathrm{MHz}, \mathrm{DMSO}-\mathrm{d}_{6}\right): \delta 114.2,124.9$, 129.2, 129.3, 130.4, 132.4, 142.3, 156.7, 164.6, 180.5. IR (ATR) v: 3321, 1636, $1507 \mathrm{~cm}^{-1}$; HRMS calcd for $\left(\mathrm{C}_{14} \mathrm{H}_{10} \mathrm{~N}_{5} \mathrm{SBr}+\mathrm{H}^{+}\right)$: 359.9919; found: 359.9914; Anal. Calcd for $\mathrm{C}_{14} \mathrm{H}_{10} \mathrm{~N}_{5} \mathrm{SBr}$ : C, 46.68; $\mathrm{H}, 2.80 ; \mathrm{N}$, 19.44. Found: $\mathrm{C}, 46.81 ; \mathrm{H}, 2.79 ; \mathrm{N}, 19.49$.

2-(4-Aminophenylazo)-5-(4-t-butylphenyl)-1,3,4-thiadiazole (4e). The product was obtained as a brown solid (2.43 g, 81\%); mp 171-173 ${ }^{\circ} \mathrm{C} ; \mathrm{R}_{\mathrm{f}}\left(\mathrm{CHCl}_{3} / \mathrm{EtOAc}\right.$ 5:1 v/v) 0.27. ${ }^{1} \mathrm{H}-\mathrm{NMR}\left(400 \mathrm{MHz}, \mathrm{DMSO}-\mathrm{d}_{6}\right)$ : $\delta 1.33\left(\mathrm{~s}, 9 \mathrm{H}, \mathrm{C}\left(\mathrm{CH}_{3}\right)_{3}\right), 6.74(\mathrm{~d}, 2 \mathrm{H}, J=8.4 \mathrm{~Hz}, 2-\mathrm{Ar}: \mathrm{H}-3, \mathrm{H}-5), 7.10\left(\mathrm{~s}, 2 \mathrm{H}, \mathrm{NH}_{2}\right), 7.58(\mathrm{~d}, 2 \mathrm{H}, J=8.8 \mathrm{~Hz}$, 5-Ar: H-3' , H-5'), 7.76 (d, 2H, J = 8.4 Hz, 2-Ar: H-2, H-6), 7.96 (d, 2H, J = 8.8 Hz, 5-Ar: H-2' , H-6' ); ${ }^{13} \mathrm{C}-\mathrm{NMR}\left(100 \mathrm{MHz}, \mathrm{DMSO}-\mathrm{d}_{6}\right): \delta 30.8,34.8,114.1,126.2,127.3,127.4,130.2,142.3,154.5,156.5,165.7$, 179.9. IR (ATR) v: $3325,1621,1507 \mathrm{~cm}^{-1}$; HRMS calcd for $\left(\mathrm{C}_{18} \mathrm{H}_{19} \mathrm{~N}_{5} \mathrm{~S}+\mathrm{H}^{+}\right)$: 338.1440; found: 338.1438; Anal. Calcd for $\mathrm{C}_{18} \mathrm{H}_{19} \mathrm{~N}_{5} \mathrm{~S}$ : C, 64.07; H, 5.68; N, 20.75. Found: C, 64.21; H, 5.70; N, 20.71.

3.2.4. General procedure for the synthesis of

2-[4-(N,N-dimethylamino)phenylazo]-5-phenyl-1,3,4-thiadiazole derivatives (5a-e)

Sodium nitrite $(1.31 \mathrm{~g}, 0.019 \mathrm{~mol})$ was introduced portion wise into concentrated sulfuric acid $(20 \mathrm{~mL})$. The solution was heated to $50{ }^{\circ} \mathrm{C}$ in a water bath until complete dissolution and then rapidly cooled in an ice/salt bath to $0{ }^{\circ} \mathrm{C}$. In the meantime, a solution of the appropriate 2-amino-5-aryl-1,3,4-thiadiazole $3 \mathbf{a}-\mathbf{e}(0.015 \mathrm{~mol})$ in glacial acetic acid $(30 \mathrm{~mL})$ and propionic acid $(15 \mathrm{~mL})$ was prepared and added dropwise to an agitated solution of sodium nitrite in concentrated sulfuric acid at $0-5{ }^{\circ} \mathrm{C}$. Then, the mixture was stirred for $24 \mathrm{~h}$ and excess nitrous acid was decomposed by the addition of urea. The resulting diazonium salt solution was slowly introduced into the mixture of $\mathrm{N}, \mathrm{N}$-dimethylaniline $(1.90 \mathrm{~mL}, 1.82 \mathrm{~g}, 0.015 \mathrm{~mol})$ in $15 \mathrm{~mL}$ of water at $0-5^{\circ} \mathrm{C}$. The colored mixture was stirred at room temperature for the next $24 \mathrm{~h}$ and finally neutralized with saturated sodium carbonate solution $(75 \mathrm{~mL})$. The solid was filtered off, washed twice with hot water $(2 \times 25 \mathrm{~mL})$ and dried in air. The crude product (5a-e) was purified by column chromatography on silica gel $\left(\mathrm{CHCl}_{3} / \mathrm{EtOAc}\right.$ 5:1 v/v).

2-[4-(N,N-Dimethylamino)phenylazo]-5-phenyl-1,3,4-thiadiazole (5a). The product was obtained as a brown solid (3.20 g, 69\%); mp 194-195 ${ }^{\circ} \mathrm{C}\left(191^{\circ} \mathrm{C}\right.$ [26]); $\mathrm{R}_{\mathrm{f}}\left(\mathrm{CHCl}_{3} / \mathrm{EtOAc}, 5: 1 \mathrm{v} / \mathrm{v}\right)$ 0.32. IR (ATR) v: 1603, $1525 \mathrm{~cm}^{-1}$; Anal. Calcd for $\mathrm{C}_{16} \mathrm{H}_{15} \mathrm{~N}_{5} \mathrm{~S}$ : C, 62.11; H, 4.89; N, 22.64. Found: $\mathrm{C}, 62.08 ; \mathrm{H}, 4.86 ; \mathrm{N}, 22.67$.

2-[4-(N,N-Dimethylamino)phenylazo]-5-(4-methoxyphenyl)-1,3,4-thiadiazole (5b). The product was obtained as a dark red solid (3.00 g, 59\%); mp 219-221 ${ }^{\circ} \mathrm{C} ; \mathrm{R}_{\mathrm{f}}\left(\mathrm{CHCl}_{3} / \mathrm{EtOAc}, 5: 1 \mathrm{v} / \mathrm{v}\right)$ 0.27. ${ }^{1} \mathrm{H}-\mathrm{NMR}$ $\left(400 \mathrm{MHz}, \mathrm{DMSO}-\mathrm{d}_{6}\right): \delta 3.17\left(\mathrm{~s}, 6 \mathrm{H}, \mathrm{N}\left(\mathrm{CH}_{3}\right)_{2}\right), 3.86\left(\mathrm{~s}, 3 \mathrm{H}, \mathrm{OCH}_{3}\right), 6.92(\mathrm{~d}, 2 \mathrm{H}, J=9.2 \mathrm{~Hz}, 2-\mathrm{Ar}: \mathrm{H}-3$, H-5), 7.12 (d, 2H, J = 8.8 Hz, 5-Ar: H-3' , H-5'), 7.85 (d, 2H, J = 9.2 Hz, 2-Ar: H-2, H-6), 7.99 (d, 2H, $\left.J=8.8 \mathrm{~Hz}, 5-\mathrm{Ar}: \mathrm{H}-2^{\prime}, \mathrm{H}^{\prime} 6^{\prime}\right) ;{ }^{13} \mathrm{C}-\mathrm{NMR}\left(100 \mathrm{MHz}, \mathrm{DMSO}^{-} \mathrm{d}_{6}\right): \delta 40.2,55.5,112.2,114.8,122.5,126.0$, 129.2, 129.4, 142.0, 154.6, 164.8, 179.4. IR (ATR) v: $1603,1516 \mathrm{~cm}^{-1}$; HRMS calcd for $\left(\mathrm{C}_{17} \mathrm{H}_{17} \mathrm{~N}_{5} \mathrm{SO}+\mathrm{H}^{+}\right)$: 
340.1232; found: 340.1233; Anal. Calcd for $\mathrm{C}_{17} \mathrm{H}_{17} \mathrm{~N}_{5} \mathrm{SO}$ : $\mathrm{C}, 60.16 ; \mathrm{H}, 5.05 ; \mathrm{N}, 20.63$. Found: $\mathrm{C}, 60.27 ; \mathrm{H}$, $5.03 ; \mathrm{N}, 20.61$.

2-[4-(N,N-Dimethylamino)phenylazo]-5-(4-nitrophenyl)-1,3,4-thiadiazole (5c). The product was obtained as a brown solid (3.19 g, 60\%); mp 169-171 ${ }^{\circ} \mathrm{C} ; \mathrm{R}_{\mathrm{f}}\left(\mathrm{CHCl}_{3} / \mathrm{EtOAc}, 5: 1 \mathrm{v} / \mathrm{v}\right)$ 0.38. ${ }^{1} \mathrm{H}-\mathrm{NMR}$ $\left(400 \mathrm{MHz}, \mathrm{DMSO}-\mathrm{d}_{6}\right): \delta 3.18\left(\mathrm{~s}, 6 \mathrm{H}, \mathrm{N}\left(\mathrm{CH}_{3}\right)_{2}\right), 7.04(\mathrm{~d}, 2 \mathrm{H}, J=8.8 \mathrm{~Hz}, 2-\mathrm{Ar}: \mathrm{H}-3, \mathrm{H}-5), 7.96(\mathrm{~d}, 2 \mathrm{H}$, $\left.J=9.2 \mathrm{~Hz}, 5-\mathrm{Ar}: \mathrm{H}-3^{\prime}, \mathrm{H}-5^{\prime}\right), 8.37-8.40$ (m, 4H, 2-Ar, 5-Ar: H-2, H-6, H-2' $\left.{ }^{\prime} \mathrm{H}-6^{\prime}\right) ;{ }^{13} \mathrm{C}-\mathrm{NMR}(100 \mathrm{MHz}$, DMSO-d $_{6}$ ): $\delta 40.0,112.3,124.4,124.5,126.9,129.1,130.1,142.1,155.5,164.8,179.8$. IR (ATR) $v$ : 1597, $1516 \mathrm{~cm}^{-1}$; HRMS calcd for $\left(\mathrm{C}_{16} \mathrm{H}_{14} \mathrm{~N}_{6} \mathrm{SO}_{2}+\mathrm{H}^{+}\right)$: 355.0977; found: 355.0979; Anal. Calcd for $\mathrm{C}_{16} \mathrm{H}_{14} \mathrm{~N}_{6} \mathrm{SO}_{2}$ : C, 54.23; $\mathrm{H}, 3.98 ; \mathrm{N}, 23.71$. Found: $\mathrm{C}, 54.40 ; \mathrm{H}, 3.99 ; \mathrm{N}, 23.76$.

5-(4-Bromophenyl)-2-[4-(N,N-dimethylamino)phenylazo]-1,3,4-thiadiazole $(5 \mathbf{d}) . \quad$ The product was obtained as a dark violet solid $(3.49 \mathrm{~g}, 60 \%) ; \mathrm{mp} 201-203{ }^{\circ} \mathrm{C} ; \mathrm{R}_{\mathrm{f}}\left(\mathrm{CHCl}_{3} / \mathrm{EtOAc}, 5: 1 \mathrm{v} / \mathrm{v}\right)$ 0.40. ${ }^{1} \mathrm{H}-\mathrm{NMR}$ $\left(400 \mathrm{MHz}, \mathrm{DMSO}-\mathrm{d}_{6}\right): \delta 3.18\left(\mathrm{~s}, 6 \mathrm{H}, \mathrm{N}\left(\mathrm{CH}_{3}\right)_{2}\right), 6.91$ (d, 2H, J = 9.2 Hz, 2-Ar: H-3, H-5), 7.77 (d, 2H, $\left.J=8.4 \mathrm{~Hz}, 5-\mathrm{Ar}: \mathrm{H}-3^{\prime}, \mathrm{H}-5^{\prime}\right), 7.84$ (d, 2H, $\left.J=9.2 \mathrm{~Hz}, 2-\mathrm{Ar}: \mathrm{H}-2, \mathrm{H}-6\right), 7.97$ (d, 2H, $J=8.4 \mathrm{~Hz}, 5-\mathrm{Ar}: \mathrm{H}-2^{\prime}$, H-6 $\left.{ }^{\prime}\right) ;{ }^{13} \mathrm{C}-\mathrm{NMR}\left(100 \mathrm{MHz}\right.$, DMSO-d $\left.{ }_{6}\right): \delta 40.0,112.3,124.9,128.8,129.2,129.3,132.4,142.1,154.8,164.7$, 180.5. IR (ATR) v: 1597, $1522 \mathrm{~cm}^{-1}$; HRMS calcd for $\left(\mathrm{C}_{16} \mathrm{H}_{14} \mathrm{~N}_{5} \mathrm{SBr}+\mathrm{H}^{+}\right)$: 388.0232; found: 388.0238 ; Anal. Calcd for $\mathrm{C}_{16} \mathrm{H}_{14} \mathrm{~N}_{5} \mathrm{SBr}$ : C, 49.49; H, 3.63; N, 18.04. Found: C, 49.37; H, 3.66; N, 18.09.

5-(4-t-Butylphenyl)-2-[4-(N,N-dimethylamino)phenylazo]-1,3,4-thiadiazole (5e). The product was obtained as a dark violet solid ( $3.07 \mathrm{~g}, 56 \%) ; \mathrm{mp} 225-227^{\circ} \mathrm{C} ; \mathrm{R}_{\mathrm{f}}\left(\mathrm{CHCl}_{3} / \mathrm{EtOAc}, 5: 1 \mathrm{v} / \mathrm{v}\right)$ 0.39. ${ }^{1} \mathrm{H}-\mathrm{NMR}$ $\left(400 \mathrm{MHz}, \mathrm{DMSO}-\mathrm{d}_{6}\right): \delta 1.33\left(\mathrm{~s}, 9 \mathrm{H}, \mathrm{C}\left(\mathrm{CH}_{3}\right)_{3}\right), 3.18\left(\mathrm{~s}, 6 \mathrm{H}, \mathrm{N}\left(\mathrm{CH}_{3}\right)_{2}\right), 6.93(\mathrm{~d}, 2 \mathrm{H}, J=9.2 \mathrm{~Hz}, 2-\mathrm{Ar}: \mathrm{H}-3$, H-5), 7.59 (d, 2H, J = 8.4 Hz, 5-Ar: H-3' , H-5'), 7.86 (d, 2H, J = 9.2 Hz, 2-Ar: H-2, H-6), 7.97 (d, 2H, $\left.J=8.4 \mathrm{~Hz}, 5-\mathrm{Ar}: \mathrm{H}-2^{\prime}, \mathrm{H}-6^{\prime}\right) ;{ }^{13} \mathrm{C}-\mathrm{NMR}\left(100 \mathrm{MHz}, \mathrm{DMSO}^{-\mathrm{d}_{6}}\right): \delta 30.8,34.8,40.1,112.3,126.2,127.4$, 127.6, 142.1, 153.4, 154.5, 154.7, 165.8, 179.8. IR (ATR) v: 1604, $1524 \mathrm{~cm}^{-1}$; Anal. Calcd for $\mathrm{C}_{20} \mathrm{H}_{23} \mathrm{~N}_{5} \mathrm{~S}$ : HRMS calcd for $\left(\mathrm{C}_{20} \mathrm{H}_{23} \mathrm{~N}_{5} \mathrm{~S}+\mathrm{H}^{+}\right)$: 366.1752; found: 366.1754; Anal. Calcd for $\mathrm{C}_{20} \mathrm{H}_{23} \mathrm{~N}_{5} \mathrm{~S}: \mathrm{C}, 65.72 ; \mathrm{H}$, 6.34; N, 19.16. Found: C, 65.80; H, 6.33; N, 19.18.

3.2.5. General Procedure for the Synthesis of 2-(4-Hydroxyphenylazo)-5-phenyl-1,3,4-thiadiazole Derivatives (6a-e)

Sodium nitrite $(1.31 \mathrm{~g}, 0.019 \mathrm{~mol})$ was introduced portion wise into concentrated sulfuric acid $(20 \mathrm{~mL})$. The solution was heated to $50{ }^{\circ} \mathrm{C}$ in a water bath until complete dissolution and then rapidly cooled in an ice/salt bath to $0{ }^{\circ} \mathrm{C}$. In the meantime, a solution of the appropriate 2-amino-5-aryl-1,3,4-thiadiazole $3 a-e(0.015 \mathrm{~mol})$ in glacial acetic acid $(30 \mathrm{~mL})$ and propionic acid $(15 \mathrm{~mL})$ was prepared and added dropwise to an agitated solution of sodium nitrite in concentrated sulfuric acid at $0-5{ }^{\circ} \mathrm{C}$. Then, the mixture was stirred for $24 \mathrm{~h}$ and excess nitrous acid was decomposed by the addition of urea. The resulting diazonium salt solution was slowly introduced into the mixture of phenol $(1.41 \mathrm{~g}, 0.015 \mathrm{~mol})$ in $15 \mathrm{~mL}$ of water at $0-5^{\circ} \mathrm{C}$. The colored mixture was stirred at room temperature for $24 \mathrm{~h}$ and finally neutralized with saturated sodium carbonate solution $(75 \mathrm{~mL})$. The solid was filtered off, washed twice with hot water $(2 \times 25 \mathrm{~mL})$ and dried in air. The crude product (6a-e) was purified by column chromatography on silica gel $\left(\mathrm{CHCl}_{3} / \mathrm{EtOAc}, 5: 1 \mathrm{v} / v\right)$.

2-(4-Hydroxyphenylazo)-5-phenyl-1,3,4-thiadiazole (6a). The product was obtained as a red solid (3.47 g, 82\%); mp 200-202 ${ }^{\circ} \mathrm{C}\left(196-198^{\circ} \mathrm{C}\right.$ [25]); $\mathrm{R}_{\mathrm{f}}\left(\mathrm{CHCl}_{3} / \mathrm{EtOAc}, 5: 1\right.$ v/v) 0.25. IR (ATR) v: 3060, 1608, $1512 \mathrm{~cm}^{-1}$; Anal. Calcd for $\mathrm{C}_{14} \mathrm{H}_{10} \mathrm{~N}_{4} \mathrm{OS}: \mathrm{C}, 59.56 ; \mathrm{H}, 3.57 ; \mathrm{N}, 19.85$. Found: $\mathrm{C}, 59.50 ; \mathrm{H}, 3.52 ; \mathrm{N}, 19.87$.

2-(4-Hydroxyphenylazo)-5-(4-methoxyphenyl)-1,3,4-thiadiazole (6b). The product was obtained as an orange solid $(4.26 \mathrm{~g}, 91 \%) ; \mathrm{mp} 271-273{ }^{\circ} \mathrm{C} ; \mathrm{R}_{\mathrm{f}}\left(\mathrm{CHCl}_{3} / \mathrm{EtOAc}, 5: 1 \mathrm{v} / v\right)$ 0.23. ${ }^{1} \mathrm{H}-\mathrm{NMR}(400 \mathrm{MHz}$, DMSO-d $\left.{ }_{6}\right): \delta 3.86\left(\mathrm{~s}, 3 \mathrm{H}, \mathrm{OCH}_{3}\right), 7.02(\mathrm{~d}, 2 \mathrm{H}, J=9.2 \mathrm{~Hz}, 2-\mathrm{Ar}: \mathrm{H}-3, \mathrm{H}-5), 7.13(\mathrm{~d}, 2 \mathrm{H}, J=8.8 \mathrm{~Hz}$, 5-Ar: H-3' , H-5'), 7.92 (d, 2H, J = 9.2 Hz, 2-Ar: H-2, H-6), 8.03 (d, 2H, J = 8.8 Hz, 5-Ar: H-2' , H-6'); ${ }^{13}$ C-NMR (100 MHz, DMSO-d $\left.{ }_{6}\right): \delta 55.5,114.9,116.7,122.1,126.8,129.6,144.7,162.2,164.1,167.3,178.4$. IR (ATR) v: 3099, 1601, $1518 \mathrm{~cm}^{-1}$; HRMS calcd for $\left(\mathrm{C}_{15} \mathrm{H}_{12} \mathrm{~N}_{4} \mathrm{SO}_{2}+\mathrm{H}^{+}\right)$: 313.0759; found: 313.0755; Anal. Calcd for $\mathrm{C}_{15} \mathrm{H}_{12} \mathrm{~N}_{4} \mathrm{SO}_{2}$ : C, 57.68; H, 3.87; N, 17.94. Found: C, 57.59; H, 3.85; N, 17.99.

2-(4-Hydroxyphenylazo)-5-(4-nitrophenyl)-1,3,4-thiadiazole (6c). The product was obtained as a dark brown solid (3.92 g, 80\%); mp 258-260 ${ }^{\circ} \mathrm{C}$; $\mathrm{R}_{\mathrm{f}}\left(\mathrm{CHCl}_{3} / \mathrm{EtOAc}, 5: 1 \mathrm{v} / v\right)$ 0.35. ${ }^{1} \mathrm{H}-\mathrm{NMR}(400 \mathrm{MHz}$, 
DMSO-d $\left.)_{6}\right): \delta 6.97(\mathrm{~d}, 2 \mathrm{H}, J=8.8 \mathrm{~Hz}, 2-\mathrm{Ar}: \mathrm{H}-3, \mathrm{H}-5), 7.92\left(\mathrm{~d}, 2 \mathrm{H}, J=8.8 \mathrm{~Hz}, 5-\mathrm{Ar}: \mathrm{H}-3^{\prime}, \mathrm{H}^{-} 5^{\prime}\right)$, 8.28-8.40 (m, 4H, 2-Ar, 5-Ar: H-2, H-6, H-2', H-6 $\left.{ }^{\prime}\right) ;{ }^{13} \mathrm{C}-\mathrm{NMR}\left(100 \mathrm{MHz}, \mathrm{DMSO}-\mathrm{d}_{6}\right): \delta 117.4,124.4$, 124.6, 127.5, 129.0, 144.7, 157.3, 164.1, 167.4, 179.1. IR (ATR) v: 3080, 1598, $1515 \mathrm{~cm}^{-1}$; HRMS calcd for $\left(\mathrm{C}_{14} \mathrm{H}_{9} \mathrm{~N}_{5} \mathrm{SO}_{3}+\mathrm{H}^{+}\right)$: 328.0504; found: 328.0502; Anal. Calcd for $\mathrm{C}_{14} \mathrm{H}_{9} \mathrm{~N}_{5} \mathrm{SO}_{3}: \mathrm{C}, 51.37 ; \mathrm{H}, 2.77 ; \mathrm{N}$, 21.40. Found: C, 51.50; H, 2.78; N, 21.47.

5-(4-Bromophenyl)-2-(4-hydroxyphenylazo)-1,3,4-thiadiazole (6d). The product was obtained as a brown solid (4.06 g, 75\%); mp 263-265 ${ }^{\circ} \mathrm{C}$; $\mathrm{R}_{\mathrm{f}}\left(\mathrm{CHCl}_{3} / \mathrm{EtOAc}, 5: 1 \mathrm{v} / v\right)$ 0.33. ${ }^{1} \mathrm{H}-\mathrm{NMR}(400 \mathrm{MHz}$, DMSO-d $\left.)_{6}\right) \delta 7.03(\mathrm{~d}, 2 \mathrm{H}, \mathrm{J}=9.2 \mathrm{~Hz}, 2-\mathrm{Ar}: \mathrm{H}-3, \mathrm{H}-5), 7.80\left(\mathrm{~d}, 2 \mathrm{H}, J=8.8 \mathrm{~Hz}, 5-\mathrm{Ar}: \mathrm{H}-3^{\prime}, \mathrm{H}_{-} 5^{\prime}\right)$, $7.94(\mathrm{~d}, 2 \mathrm{H}, J=9.2 \mathrm{~Hz}, 2-\mathrm{Ar}: \mathrm{H}-2, \mathrm{H}-6), 8.03$ (d, 2H, J = 8.8 Hz, 5-Ar: H-2' , H-6' $)$; ${ }^{13} \mathrm{C}-\mathrm{NMR}(100 \mathrm{MHz}$, DMSO-d 6 ): $\delta 116.8,125.5,127.1,129.6,131.7,132.5,144.7,164.4,166.4,179.4$. IR (ATR) v: 3047, 1587, $1507 \mathrm{~cm}^{-1}$; HRMS calcd for $\left(\mathrm{C}_{14} \mathrm{H}_{9} \mathrm{~N}_{4} \mathrm{SOBr}+\mathrm{H}^{+}\right)$: 360.9759; found: 360.9757; Anal. Calcd for $\mathrm{C}_{14} \mathrm{H}_{9} \mathrm{~N}_{4} \mathrm{SOBr}: \mathrm{C}, 46.55 ; \mathrm{H}, 2.51 ; \mathrm{N}, 15.51$. Found: C, 46.61; H, 2.50; N, 15.59.

5-(4-t-Butylphenyl)-2-(4-hydroxyphenylazo)-1,3,4-thiadiazole (6e). The product was obtained as an orange solid (4.06 g, 80\%); mp 291-293 ${ }^{\circ} \mathrm{C} ; \mathrm{R}_{\mathrm{f}}\left(\mathrm{CHCl}_{3} / \mathrm{EtOAc}, 5: 1 \mathrm{v} / v\right)$ 0.37. ${ }^{1} \mathrm{H}-\mathrm{NMR}(400 \mathrm{MHz}$, DMSO-d 6$): \delta 1.33\left(\mathrm{~s}, 9 \mathrm{H}, \mathrm{C}\left(\mathrm{CH}_{3}\right)_{3}\right), 7.03(\mathrm{~d}, 2 \mathrm{H}, J=9.2 \mathrm{~Hz}, 2-\mathrm{Ar}: \mathrm{H}-3$; H-5), 7.60 (d, 2H, J = 8.8 Hz, 5-Ar: H-3', $\left.\mathrm{H}-5^{\prime}\right), 7.94$ (d, 2H, $\left.J=9.2 \mathrm{~Hz}, 2-\mathrm{Ar}: \mathrm{H}-2, \mathrm{H}-6\right), 8.01$ (d, 2H, $\left.J=8.8 \mathrm{~Hz}, 5-\mathrm{Ar}: \mathrm{H}-2^{\prime}, \mathrm{H}^{\prime} 6^{\prime}\right)$; ${ }^{13} \mathrm{C}-\mathrm{NMR}$ $\left(100 \mathrm{MHz}, \mathrm{DMSO}-\mathrm{d}_{6}\right): \delta 30.8,34.8,116.7,126.3,126.9,127.6,129.6,144.8,155.1,164.1,167.5,178.8$. IR (ATR) v: 3100, 1582, $1507 \mathrm{~cm}^{-1}$; HRMS calcd for $\left(\mathrm{C}_{18} \mathrm{H}_{18} \mathrm{~N}_{4} \mathrm{SO}+\mathrm{H}^{+}\right)$: 339.1280; found: 339.1281; Anal. Calcd for $\mathrm{C}_{18} \mathrm{H}_{18} \mathrm{~N}_{4} \mathrm{SO}$ : C, 63.88; H, 5.36; N, 16.56. Found: C, 63.76; H, 5.39; N, 16.51 .

\section{Conclusions}

An efficient synthetic strategy for the preparation of new azo dyes using weak heteroaromatic amines containing a 1,3,4-thiadiazole scaffold as the diazo component and aniline, $N, N$-dimethylaniline and phenol as simultaneous coupling precursors, was presented. Three series of azo dyes, the derivatives of 2-phenylazo-5-phenyl-1,3,4-thiadiazole, were obtained in good to excellent yields. The new dyes obtained-demonstrating a broad color spectrum and good solubility in some polar solvents-may serve as potential candidates for the dye industry and will be tested in the near future.

Supplementary Materials: Copies of the 1H-NMR, 13C-NMR, UV-Vis and IR spectra of the compounds as well as figures showing the calculated spectra and the contour plots of the most important molecular orbitals are available in the online Supplementary Materials.

Author Contributions: A.K., M.O. and M.L. conceived and designed the experiments, performed the experiments and analyzed the data. M.S., T.S. and R.K. performed emission measurements, X-ray structural analysis and time-dependent density functional theory calculations. A.K. wrote the manuscript with the help of M.O. and R.K. All authors read and approved the final manuscript.

Funding: The synthetic part of the project was financially supported by the EU under the project RPO WL RPLU.01.02.00-06-1116/16. The crystallographic part was financed by funds allocated by the Ministry of Science and Higher Education to the Institute of General and Ecological Chemistry, Lodz University of Technology in Poland.

Conflicts of Interest: The authors declare no conflicts of interest.

\section{References}

1. Koutentis, P.A.; Constantinides, C.P. 1,3,4-Thiadiazoles. In Comprehensive Heterocyclic Chemistry III; Katritzky, A., Ramsden, C.A., Scriven, E.F.V., Taylor, R.J.K., Eds.; Elsevier Science Ltd.: Oxford, UK, 2008; Volume 5, pp. 567-605.

2. Hu, Y.; Li, C.; Wang, X.; Yang, Y.; Zhu, H. 1,3,4-Thiadiazole: Synthesis, reactions, and applications in medicinal, agricultural, and materials chemistry. Chem. Rev. 2014, 114, 5572-5610. [CrossRef] [PubMed]

3. Li, Y.; Geng, J.; Liu, Y.; Yu, S.; Zhao, G. Thiadiazole-A promising structure in medicinal chemistry. Chem. Med. Chem. 2013, 8, 27-41. [CrossRef] [PubMed]

4. Karaburun, A.; Acar Cevik, U.; Osmaniye, D.; Saglik, B.; Kaya Cavusoglu, B.; Levent, S.; Ozkay, Y.; Koparal, A.; Behcet, M.; Kaplancikli, Z.A. Synthesis and evaluation of new 1,3,4-thiadiazole derivatives as potent antifungal agents. Molecules 2018, 23, 3129. [CrossRef] [PubMed] 
5. Gur, M.; Sener, N.; Kastas, C.A.; Ozkan, O.E.; Muglu, H.; Elmaswaria, M.A.M. Synthesis and characterization of some new heteroaromatic compounds having chirality adjacent to a 1,3,4-thiadiazole moiety and their antimicrobial activities. J. Heterocycl. Chem. 2017, 54, 3578-3590. [CrossRef]

6. Hafez, H.N.; Hegab, M.I.; Ahmed-Farag, I.S.; El-Gazzar, A.B.A. A facile regioselective synthesis of novel spiro-thioxanthene and spiro-xanthene- $9^{\prime}, 2-[1,3,4]$ thiadiazole derivatives as potential analgesic and anti-inflammatory agents. Bioorg. Med. Chem. 2008, 18, 4538-4543. [CrossRef]

7. Altintop, M.D.; Sever, B.; Ozdemir, A.; Iglin, S.; Alti, O.; Turan-Zitouni, G.; Kaplancikli, Z.A. Synthesis and evaluation of a series of 1,3,4-thiadiazole derivatives as potential anticancer agents. Anticancer Agents Med. Chem. 2019, 18, 1606-1616. [CrossRef]

8. Richwine, J.R. 2,5-Dimercapto-1,3,4-thiadiazole as a Cross-Linker for Saturated Halogen-Containing Polymers. Inventor: Hercules Incorporated Wilmington, Assignee. U.S. Patent 4288576, 8 September 1981.

9. Jin, L.; Wang, G.; Li, X. Poly(2,5-dimercapto-1,3,4-thiadiazole)/sulfonated graphene composite as cathode material for rechargeable lithium batteries. J. Appl. Electrochem. 2011, 41, 377-382. [CrossRef]

10. Maradiya, H.R. Monoazo disperse dyes based on 2-amino-1,3,4-thiadiazole derivatives. J. Serb. Chem. Soc. 2002, 67, 709-718. [CrossRef]

11. Yan, H.; Su, H.; Tian, D.; Miao, F.; Li, H. Synthesis of triazolo-thiadiazole fluorescent organic nanoparticles as primary sensor toward $\mathrm{Ag}^{+}$and the complex of $\mathrm{Ag}^{+}$as secondary sensor toward cysteine. Sens. Actuators B Chem. 2011, 160, 656-661. [CrossRef]

12. Hipler, F.; Fischer, R.A.; Muller, J. Matrix-isolation pyrolysis investigation of mercapto-functionalized 1,3,4-thiadiazoles: Thermal stability of thiadiazole lubricant additives. Phys. Chem. Chem. Phys. 2005, 7, 731-737. [CrossRef]

13. Dawson, J.F. Developments in disperse dyes. Color. Technol. 1978, 9, 25-35. [CrossRef]

14. Arcoria, A.; De Giorgi, M.R.; Fatuzzo, F.; Longo, M.L. Dyeing properties of basic azo-dyes from 2-amino thiadiazole. Dyes Pigment. 1993, 21, 67-74. [CrossRef]

15. De Giorgi, M.R.; Carpignano, R.; Cerniani, A. Structure optimization in a series of thiadiazole disperse dyes using a chemometric approach. Dyes Pigment. 1998, 37, 187-196. [CrossRef]

16. Zollinger, H. Azo dyes and Pigments. In Color Chemistry: Syntheses, Properties, and Applications of Organic Dyes and Pigments, 3rd ed.; Viley-VCH: Zurich, Switzerland, 2003; pp. 165-254.

17. Ullrich, R.; Grewer, T. Decomposition of aromatic diazonium compounds. Thermochim. Acta 1993, 225, $201-211$. [CrossRef]

18. Zhao, R.; Tan, C.; Xie, Y.; Gao, C.; Liu, H.; Jiang, Y. One step synthesis of azo compounds from nitroaromatics and anilines. Tetrahedron Lett. 2011, 52, 3805-3809. [CrossRef]

19. Chung, T.F.; Wu, Y.M.; Cheng, C.H. Reduction of aromatic nitro compounds by ethylenediamine. A new selective reagent for the synthesis of symmetric azo compounds. J. Org. Chem. 1984, 49, 1215-1217. [CrossRef]

20. Srinivasa, G.R.; Abiraj, K.; Channe Gowda, D. Lead-catalyzed synthesis of azo compounds by ammonium acetate reduction of aromatic nitro compounds. Synth. Commun. 2003, 33, 4221-4227. [CrossRef]

21. Noureldin, N.A.; Bellegarde, J.W. A novel method. The synthesis of ketones and azobenzenes using supported permanganate. Synthesis 1999, 6, 939-942. [CrossRef]

22. Bhatnagar, I.; George, M.V. Oxidation with metal oxides. III. Oxidation of diamines and hydrazines with manganese dioxide. J. Org. Chem. 1968, 33, 2407-2411. [CrossRef]

23. Faustino, H.; El-Shisthawy, R.M.; Reis, L.V.; Santos, P.F.; Almeida, P. 2-Nitrosobenzothiazoles: Useful synthons for new azobenzothiazole dyes. Tetrahedron Lett. 2008, 49, 6907-6909. [CrossRef]

24. Tambe, S.M.; Tasaganva, R.G.; Inamdar, S.R.; Kariduraganavar, M.Y. Synthesis and characterization of nonlinear optical side-chain polyimides containing the thiadiazole chromophores. J. Appl. Pol. Sci. 2012, 125, 1049-1058. [CrossRef]

25. Tomi, I.H.R.; Al-Daraji, A.H.R.; Al-Qaysi, R.R.T.; Hasson, M.M.; Al-Dulaimy, K.H.D. Synthesis, characterization and biological activities of some azo derivatives of aminothiadiazole derived from nicotinic and isonicotinic acids. Arab. J. Chem. 2014, 7, 687-694. [CrossRef]

26. Kumar, C.T.K.; Keshavayya, J.; Rajesk, T.N.; Peethambar, S.K.; Ali, A.R.S. Synthesis, characterization, and biological activity of 5-phenyl-1,3,4-thiadiazole-2-amine incorporated azo dye derivatives. Org. Chem. Int. 2013, 370626. [CrossRef] 
27. Kedzia, A.; Kudelko, A.; Swiatkowski, M.; Kruszynski, R. Microwave-promoted synthesis of highly luminescent s-tetrazine-1,3,4-oxadiazole and s-tetrazine-1,3,4-thiadiazole hybrids. Dyes Pigment. 2020, 172, 107865. [CrossRef]

28. Wróblowska, M.; Kudelko, A.; Kuźnik, N.; Łaba, K.; Łapkowski, M. Synthesis of Extended 1,3,4-Oxadiazole and 1,3,4-Thiadiazole Derivatives in the Suzuki Cross-Coupling Reactions. J. Heterocycl. Chem. 2017, 54, 1550-1557. [CrossRef]

29. Wróblowska, M.; Kudelko, A.; Łapkowski, M. Efficient Synthesis of Conjugated 1,3,4-Thiadiazole Hybrids through Palladium-Catalyzed Cross Coupling of 2,5-Bis(4-bromophenyl)-1,3,4-thiadiazole with Boronic Acids. Synlett 2015, 26, 2127-2130. [CrossRef]

30. Mavrova, A.T.; Wesselinova, D.; Tsenov, Y.A.; Denkova, P. Synthesis, cytotoxity and effects of some 1,2,4-triazole and 1,3,4-thiadiazole derivatives on immunocompetent cells. Eur. J. Med. Chem. 2009, 44, 63-69. [CrossRef]

31. Groom, C.R.; Bruno, I.J.; Lightfoot, M.P.; Ward, S.C. The Cambridge Structural Database. Acta Crystallogr. B 2016, 72, 171-179. [CrossRef]

32. Cowley, J.M. Scattering factors for the diffraction of electrons by crystalline solids. In International Tables for Crystallography, Volume C: Mathematical, Physical and Chemical Tables, 3rd ed.; Prince, E., Ed.; Kluwer Academic Publishers: Dordrecht, The Netherlands, 2004; pp. 259-262.

33. Sheldrick, G.M. Crystal structure refinement with SHELXL. Acta Crystallogr. 2015, C71, 3-8.

34. Desiraju, G.R.; Steiner, T. The Weak Hydrogen Bond in Structural Chemistry and Biology; Oxford University Press: Oxford, UK, 1999; pp. 293-342.

35. Kruszynski, R.; Sieranski, T. Can stacking interactions exist beyond the commonly accepted limits? Cryst. Growth Des. 2016, 16, 587-595. [CrossRef]

36. Frisch, M.J.; Trucks, G.W.; Schlegel, H.B.; Scuseria, G.E.; Robb, M.A.; Cheeseman, J.R.; Scalmani, G.; Barone, V.; Mennucci, B.; Petersson, G.A.; et al. Gaussian 09, Revision, D.01; Gaussian, Inc.: Wallingford, CT, USA, 2009.

37. Grimme, S.; Ehrlich, S.; Goerigk, L. Effect of the damping function in dispersion corrected density functional theory. J. Comp. Chem. 2011, 32, 1456-1465. [CrossRef] [PubMed]

38. Tomasi, J.; Mennucci, B.; Cammi, R. Quantum mechanical continuum solvation models. Chem. Rev. 2005, 105, 2999-3093. [CrossRef]

39. Campaigne, E.; Selby, T.P. Thiazoles and thiadiazines. The condensation of ethyl 4-chloroacetoacetate with thiosemicarbazide. J. Heterocycl. Chem. 1978, 15, 401-411. [CrossRef]

40. Plumitallo, A.; Cardia, M.C.; Distinto, S.; DeLogu, A.; Maccioni, E. Synthesis and anti-microbial activity evaluation of some new 1-benzoyl-isothiosemicarbazides. Farmaco 2004, 59, 945-952. [CrossRef] [PubMed]

41. Malbec, F.; Milcent, R.; Barbier, G. Dérivés de la dihydro-2,4 triazole-1,2,4 thione-3 et de l'amino-2 thiadiazole-1,3,4 à partir de nouvelles thiosemicarbazones d'esters. J. Heterocycl. Chem. 1984, 21, 1689-1698. [CrossRef]

42. Giri, S.; Nizamuddin Srivastava, U.C. Synthesis of some N-(5-aryl/aryloxymethyl-1,3,4-thiadiazol-2-yl) glyoxylamide thiosemicarbazones as potential antiviral and antifungal agents. Agric. Biol. Chem. 1983, 47, 103-105. [CrossRef]

43. Jatav, V.; Mishra, P.; Kashaw, S.; Stables, J.P. Synthesis and CNS depressant activity of some novel 3-[5-substituted 1,3,4-thiadiazole-2-yl]-2-styryl quinazoline-4(3H)-ones. Eur. J. Med. Chem. 2008, 43, 135-141. [CrossRef] [PubMed]

44. Carvalho, A.S.; Gibaldi, D.; Pinto, A.C.; Bozza, M.; Boechat, N. Synthesis and trypanocidal evaluation of news 5-[N-(3-(5-substituted)-1,3,4-thiadiazolyl)]amino-1-methyl-4-nitroimidazoles. Lett. Drug Des. Discov. 2006, 3, 98-101. [CrossRef]

Sample Availability: Samples of the compounds $\mathbf{4 a - e}, \mathbf{5 a}-\mathbf{e}, \mathbf{6 a}-\mathbf{e}$ are available from the authors. 